\title{
Analysis of Atlantic extratropical storm tracks characteristics in 41 years of ERA5 and CFSR/CFSv2 databases
}

Article

Accepted Version

Creative Commons: Attribution-Noncommercial-No Derivative Works 4.0

Gramcianinov, C. B., Campos, R. M., de Camargo, R., Hodges, K., Guedes Soares, C. and da Silva Dias, P. L. (2020) Analysis of Atlantic extratropical storm tracks characteristics in 41 years of ERA5 and CFSR/CFSv2 databases. Ocean Engineering, 216. 108111. ISSN 0029-8018 doi: https://doi.org/10.1016/j.oceaneng.2020.108111 Available at https://centaur.reading.ac.uk/92935/

It is advisable to refer to the publisher's version if you intend to cite from the work. See Guidance on citing.

To link to this article DOI: http://dx.doi.org/10.1016/j.oceaneng.2020.108111

Publisher: Elsevier

All outputs in CentAUR are protected by Intellectual Property Rights law, including copyright law. Copyright and IPR is retained by the creators or other copyright holders. Terms and conditions for use of this material are defined in the End User Agreement. 


\section{CentAUR}

Central Archive at the University of Reading

Reading's research outputs online 


\title{
Analysis of Atlantic extratropical storm tracks characteristics in 41 years of ERA5 and CFSR/CFSv2
}

\author{
C.B. Gramcianinov ${ }^{12 *}$, R.M. Campos ${ }^{1}$, R. de Camargo ${ }^{2}$, K.I. Hodges ${ }^{3}$, C. Guedes \\ Soares ${ }^{1}$, P.L. da Silva Dias ${ }^{2}$ \\ ${ }^{1}$ Centre for Marine Technology and Ocean Engineering (CENTEC), Instituto Superior Técnico, \\ Universidade de Lisboa. Rovisco Pais, 1049-001 Lisboa, Portugal.
}

${ }^{2}$ Departamento de Ciências Atmosféricas, Instituto de Astronomia, Geofísica e Ciências Atmosféricas, Universidade de São Paulo, Rua do Matão 1226, Cidade Universitária, São Paulo, SP, Brazil.

${ }^{3}$ Department of Meteorology, University of Reading, Reading, United Kingdom.

*Corresponding Author, e-mail address: cbgramcianinov@gmail.com

ABSTRACT: This work aims to analyze and compare ERA5 and CFSR/CFSv2 from 1979 to 2019 with 1-hourly outputs, regarding their ability to reproduce storm tracks and the main characteristics of cyclones at middle and high latitudes in the North Atlantic (NA) and South Atlantic (SA) Oceans. The cyclone tracking was based on relative vorticity at $850 \mathrm{hPa}$ and the intensity is measured using the maximum 10meter wind speed. The climatology produced for both datasets shows the main characteristics of the NA and SA storm tracks, such as seasonal variability and genesis regions. The use of 1-hourly fields improves tracking in areas with complex terrains, such as the lee of Andes (SA) and Greenland (NA). The differences in cyclone numbers and characteristics between datasets are small. 92.7\% and 93.1\% of ERA5 cyclones have an identical correspondent storm in CFSR/CFSv2, in the NA and SA respectively. Genesis and lifetime statistics show that CFSR/CFSv2 may present inconsistency between forecast and analysis sequential time-steps. Large differences remain in the intensity distributions, in which the CFSR/CFSv2 presents stronger cyclones than ERA5. Divergences between the datasets decrease when the comparison is made using only CFSv2, particularly in the South Atlantic.

Keywords: Extratropical cyclones; storm tracks; cyclogenesis; South Atlantic Ocean; North Atlantic Ocean; reanalysis.

\section{Introduction}

Cyclones are key features of the day-to-day weather variability at middle and high latitudes. Storminess is an important risk for offshore structures and ship routing, particularly due to their associated extreme winds and waves (Ponce de León and Guedes Soares, 2012; Vettor and 
22 Guedes Soares, 2016; 2017). Safe and profitable engineering operations depend on weather 23 forecasts and metocean statistics, the last being usually produced from reanalysis data produced 24 by operational centers around the world (Campos et al., 2018; 2019). Transient system variability 25 in the extratropics are the contributor to not only errors in wind-wave forecasts but also for 26 problems associated with the representation of topographic and sea surface temperature gradient 27 effects in ocean models (Chelton et al., 2004). Cyclone tracks are usually obtained using 6hourly data sources, which are necessary to produce reliable cyclone tracks but are insufficient 29 for some ocean engineering problems, such as wave hindcast and forecast models. In this paper 30 cyclone tracks in the Atlantic Ocean from two modern reanalysis datasets are compared, the fifth 31 generation of reanalysis from the European Centre for Medium-Range Weather Forecast 32 (ECMWF; Hersbach and Dee, 2016) (ERA5), and the Climate Forecast System Reanalysis 33 (CFSR; Saha et al., 2011), and Climate Forecast System version 2 (CFSv2; Saha et al., 2014) 34 from the National Center for Environmental Prediction (NCEP). Besides the analysis of these two datasets and the discussion, an important contribution of this work is to produce a cyclone database that can be used to support ocean engineering and coastal hazard estimations, together with an evaluation of the main differences between the two datasets.

Automated methods for cyclone identification and tracking have been developed in the past decades, due to the increase of available data produced by Global Circulation Models (GCMs) and reanalyses, led by the improvement of computational resources. These objective methods are 41 based on a Lagrangian approach that generally uses low-level vorticity or surface pressure 42 criteria to identify and track cyclones (e.g., Murray and Simmonds, 1991; Sinclair, 1994; 43 Hodges, 1994; 1995). Since then, a wide set of cyclone climatologies have been produced for the 44 Northern Hemisphere (e.g., Hoskins and Hodges, 2002), Southern Hemisphere (e.g., Jones and 
45 Simmonds 1993; Sinclair 1994; Simmonds and Keay, 2000; Hoskins and Hodges, 2005), North 46 Atlantic (e.g., Pinto et al., 2005; Trigo, 2006; Dacre and Gray, 2009, Grise et al., 2013), and 47 South Atlantic Oceans (e.g., Mendes et al., 2010, Reboita et al., 2010, Gramcianinov et al., 48 2019). The basic product of the tracking method is the collection of cyclone trajectories within a defined region and period. The spatial statistic distribution of this collection of trajectories defines the storm track position - the preferred location of cyclone propagation.

Following the development of GCMs, the use of analyses and reanalyses was a valuable improvement to the atmosphere and ocean dynamics studies (Parker, 2016). Reanalysis products are based on a model allied to data assimilation, and thus, can provide a complete spatial coverage at a regular resolution. Despite the verification and validation performed by development centers (e.g., Kalnay et al., 1996; Saha et al., 2011; 2014), it is important to evaluate the performance of these datasets for particular applications, such as extratropical and tropical cyclones, and precipitation. Several studies have carried out intercomparisons of storm tracks obtained from different datasets for the whole globe (e.g., Hodges et al., 2003; 2011), Northern Hemisphere (e.g., Raible et al., 2008), North Atlantic sector (e.g., Trigo, 2006) and South Atlantic sector (Reboita et al., 2018; Crespo et al., 2020a). Hodges et al. (2011) compared the storm track distribution and intensity in four reanalysis: the Modern Era RetrospectiveReanalysis for Research and Applications (MERRA; Rienecker et al., 2011), the 25-yr Japan Reanalysis (JRA25; Onogi et al., 2007), the ECMWF Interim Reanalysis (ERA-Interim; Simmons et al. 2007), and the CFSR. They found larger discrepancies between the older and newer products and attributed their findings to the improvement of data assimilation techniques and increase of resolution. According to them, modern reanalysis inter compares better than the older ones for cyclone densities. However, differences remain large between CFSR and ERA- 
68 Interim for cyclones intensities, and also for densities in some regions of the Southern 69 Hemisphere. Stopa and Cheung (2014) evaluated 30 years of wind and wave data from the CFSR and ERA-Interim using altimeter and buoy observations. While ERA-Interim presented lower error metrics, CFSR showed a better performance in the upper percentiles associated with extreme events. The large differences between datasets are generally associated with the failure in the representation of extreme events (e.g., Stopa and Cheung, 2014; Campos et al., 2018). Winds are often underestimated at some locations, mainly in the Southern Hemisphere, due to the lack of observational data (e.g., Stopa and Cheung, 2014). This problem contributes to the misrepresentation of cyclones, particularly the most intense ones, which leads to issues in windwave climate hindcast and forecast (e.g., Kumar et al., 2003; Campos and Guedes Soares, 2016; 2017; Bakhtyar et al., 2018; Mattioli et al., 2019; Campos et al., 2019), and storm surge estimations (e.g., Colle et al., 2010; Booth et al., 2016; Sebastian et al., 2019).

$$
\text { Therefore, it is important to evaluate cyclone and storm track characteristics of datasets }
$$
available at high temporal resolution, since 1-hourly fields are frequently used to support the production of wave hindcasts and forecasts, and energy sector assessments. The main goal of this study is to present and evaluate the Atlantic cyclone climatology for middle and high latitudes that can be used by research and industry applications, since there is a lack of this type of product available (e.g., Dacre et al., 2012), particularly for the South Atlantic Ocean. Therefore, two main questions for this study are: (1) How does the 1-hourly ERA5 and CFSR/CFSv2 cyclone tracks for the Atlantic storm track compare with previously published studies?; (2) What are the main differences between the two datasets regarding the basic cyclone and storm track characteristics? The analysis is focused on the mean characteristics, spatial distribution and intensity of the cyclones, which are important features that control the wind and wave climates. 


\section{Data and Methods}

\subsection{Datasets}

ERA5 is the latest reanalysis produced by ECMWF, available from the Copernicus Climate Change Service (CS3). This reanalysis has been produced using 4D-Var data assimilation in ECMWF's Integrated Forecast System (IFS), version CY41R2. The atmospheric variables used in this work are on a $31 \mathrm{~km}\left(0.28125^{\circ}\right)$ horizontal grid with 1-hourly outputs from 1979 to 2020 . ERA5 replaces the ERA-Interim, and benefits from its antecessor's development in model physics, core dynamics and data assimilation. One of the most important innovations of ERA5 is output of hourly analyses that can widely support risk and operational management in diverse sectors, such as renewable energy (e.g., Olauson, 2018). Moreover, Belmonte Rivas and Stoffelen (2019) found that ERA5 surface winds present a $20 \%$ improvement relative to ERAInterim, using ASCAT observations as verification. An overview of the main characteristics of ERA5 and a comparison with ERA-Interim can be found in Hersbach et al. (2018).

The CFSR is the latest version of the NCEP climate reanalysis and covers the period from 1979-March/2011. The reanalysis was produced using a coupled atmosphere-ocean model: the NCEP Global Forecast System (GFS) for the atmosphere and the Geophysical Fluid Dynamics Laboratory Modular Ocean Model version 4 (MOM4) for the ocean (Saha et al., 2010). The CFSv2, the operational descendant of the CFSR, was released in March 2011, and it has been running operationally since then. The CFSR and CFSv2 have a horizontal native resolution of $\mathrm{T} 382(\sim 38 \mathrm{~km})$ interpolated to a $0.5^{\circ} \times 0.5^{\circ}$ grid. Both the reanalysis and analysis are produced originally in 6-hourly intervals, but a 1-hourly time series are also available from some variables and consist of the analysis followed by the sequence of hourly forecasts until the next analysis 
114 cycle. The hourly sequence provided might have abrupt changes in atmospheric fields every time 115 when a forecast time-step changes to analysis time-step, since the last is corrected by data 116 assimilation. Despite this eventual inconsistency along the period, it is important to evaluate the

117 hourly data since these products are used for ocean engineering applications. Moreover, it is the 118 only way to compare CFSR/CFSv2 with ERA5 1-hourly data. Differences between products are 119 expected and need to be discussed to support future choices and/or changes.

\subsection{Cyclone identification and tracking}

The cyclones are identified and tracked in both reanalyses using the TRACK program this reason, the use of vorticity allows the early identification of cyclones that would only be

134 spectral representation and truncating to T42, tapering the spectral coefficients to smooth the 135 data. Large-scale atmospheric features were also removed by setting zonal wavenumbers $\leq 5$ to 136 zero. Hoskins and Hodges (2002) present more details about the filtering. 
The cyclonic features are identified by determining the local maxima. In the Southern Hemisphere, where negative vorticity indicates cyclonic circulation, the vorticity fields are first scaled by -1 . First, the central position of the cyclonic feature is determined by the grid point maxima that exceed a threshold of $1 \times 10^{-5} \mathrm{~s}^{-1}$ (1 cyclonic vorticity unit (CVU)) on a polar 141 stereographic projection. This identification threshold is suitable to capture even weak cyclonic 142 centers in the filtered vorticity field (T42), since it is smoother than the original vorticity one 143 (e.g., Hoskins and Hodges, 2002; 2005). The feature central locations are refined by computing 144 the off-grid maxima using B-spline interpolation and steepest descent maximization and then 145 converted back to spherical coordinates. The tracking is initialized using a nearest neighbors 146 search method. The initial set of tracks is refined by minimizing a cost function for track 147 smoothness, subject to adaptive constraints (Hodges, 1999), that operates both forwards and 148 backward in time. The high time resolution reduces ambiguity during tracking. The displacement 149 constraint applied was $2.0^{\circ}$, except in the tropics $\left(20^{\circ} \mathrm{N}-20^{\circ} \mathrm{S}\right)$ where it was set as $0.5^{\circ}$. Due to 150 the large amount of data, the tracking was performed using monthly files. Thus, post-processing 151 was applied to connect tracks between the months, using the same displacements rules described 152 above.

Finally, identified systems that are not cyclones were excluded. In this step, cyclonic features, 154 such as thermal lows, mesoscale storms, and some convergence areas were removed by 155 considering only systems that last at least 24 hours and that travel further than $1000 \mathrm{~km}$, such as 156 used by Gramcianinov et al. (2019) for the South Atlantic Ocean. The thresholds are more 157 relaxed than the ones commonly used in North Atlantic storm track studies (e.g., Hoskins and 158 Hodges, 2002; 2005; Hodges et al., 2011; Dacre and Gray, 2009), but it maintains consistency 159 throughout the entire Atlantic. The use of a higher minimum lifetime threshold (e.g., 36h or 48h) 
160 would exclude some systems with regional importance (e.g., Gramcianinov et al., 2019; 2020).

161 Gramcianinov et al. (2020) considered cyclones with a minimum of $12 \mathrm{~h}$ lifetime and $500 \mathrm{~km}$

162 displacement, to include short-lived systems that might be important for extreme waves along the

163 Southern Brazilian coast. However, the use of such a low displacement threshold results in

164 including continental lows and non-developed cyclonic systems in the climatology. Figure 1

165 shows the genesis and track densities of cyclonic systems that live at least 24 hours with the total

166 displacement between 500 and $1000 \mathrm{~km}$. In the North Atlantic, 23\% (ERA5) and 26\%

167 (CFSR/CFSv2) of the cyclonic systems were excluded with the $1000 \mathrm{~km}\left(\sim 10^{\circ}\right)$ displacement 168 threshold, while in the South Atlantic they represented a smaller portion of 15\% (ERA5) and $16921 \%$ (CFSR/CFSv2). Although these values can be considered important, the track density 170 reveals that systems with small mobility (semi-stationary) are mainly continental and thermal 171 lows generated in complex terrain, and troughs that are generated in frontal zones, without 172 enough forcing for full-development. The genesis densities are smaller when compared to active 173 cyclone genesis regions reported in the literature (e.g., Hoskins and Hodges, 2002; 2005), and 174 the track density is restricted to the generation point revealing the small influence of the systems, 175 which mostly do not reach the ocean.

176 Since the main interest of this work is on cyclones at middle and high latitude, we considered 177 for further analysis storms which pass within the extratropical latitudes of the South Atlantic $178\left(85^{\circ} \mathrm{S}-25^{\circ} \mathrm{S}, 75^{\circ} \mathrm{W}-20^{\circ} \mathrm{E}\right)$ and North Atlantic $\left(85^{\circ} \mathrm{N}-25^{\circ} \mathrm{N}, 65^{\circ} \mathrm{W}-0^{\circ} \mathrm{E}\right)$. The selected domains 179 include areas where occurs subtropical cyclones generated both by genuine subtropical genesis 180 and by transition process between tropical and extratropical cyclones (e.g., Guishard et al., 2009;

181 Evans and Braun, 2012; Gozzo et al., 2014). In this way, subtropical cyclones may be included in 
182 the set of tracks, since no distinction between subtropical and extratropical cyclones was made in 183 the present work.

\subsection{Cyclone diagnostics}

The statistical analysis consists of information for the tracks, including mean lifetime of

187 cyclones, cyclone speed, and displacement. Standard seasons are used for the entire period 188 (1979-2019): December-February (DJF), March-May (MAM), June-August (JJA), and 189 September-November (SON). Spatial statistics are computed for each reanalysis using the 190 spherical kernel estimator approach, described by Hodges (1996). The differences between track 191 and genesis densities of the two datasets were tested using Monte Carlo significance test 192 (Hodges, 2008) with 1000 samples of the set of tracks for each dataset.

194 speed is added to each track by a general search for the maximum value within a $6^{\circ}$ radius of 195 cyclone center (Bengtsson et al., 2009). This additional information was used to construct 196 maximum intensity distributions for both ERA5 and CFSR/CFSv2. Moreover, identification of 197 matched tracks between the datasets was made to perform a more direct comparison of the 198 cyclone intensities. A storm was considered to be the same in ERA5 and CFSR/CFSv2 when the 199 mean separation distance between cores was less than $2^{\circ}$ (geodesic) and they overlap in time by 200 at $50 \%$ of their points. The criteria used here is stricter than the one applied in Hodges et al. 201 (2011), where the minimum mean separation distance was $4^{\circ}$. The choice of a smaller distance 202 agrees with the focus of this work, linked to ocean engineering applications, in which smaller 203 differences in the system position may lead to large biases in the wind and wave fields. 


\section{Results}

\subsection{Genesis and track densities}

Before the direct comparison between storms tracks in each dataset, the climatology of the cyclones is presented, using ERA5 as a reference, to provide an overview of the storm track pattern and genesis variability in the North and South Atlantic Oceans.

\subsubsection{North Atlantic}

The track and genesis densities in the North Atlantic domain for the entire period, boreal winter (DJF) and summer (JJA) are shown for the ERA5 and CFSR/CFSv2 in Figure 2 and Figure 3. The North Atlantic storm track is represented by the region of maximum track density [> 10 cyclones $\left(10^{-6}, \mathrm{~km}^{2}\right)^{-1}$ (month $)^{-1}$ ] extending northeastward, from the East of North American coast to Greenland and North Europe. A northern path of the storm track strengthens in DJF, along the eastern side of Greenland, due to the increase in genesis activity at this location. The genesis density shows four regions favorable to cyclogenesis [> 2 cyclones $\left(10^{-6}, \mathrm{~km}^{2}\right)^{-1}$ (month) ${ }^{-1}$ ]: lee of the southern Rockies $\left(35^{\circ} \mathrm{N}, 102.5^{\circ} \mathrm{W}\right)$, West Atlantic $\left(40^{\circ} \mathrm{N}, 75^{\circ} \mathrm{W}\right)$, East Atlantic (centered at $50^{\circ} \mathrm{N}, 25^{\circ} \mathrm{W}$ ), and in the eastern coast of Greenland.

All genesis regions within the North Atlantic domain are more active during the boreal winter (DJF). However, the genesis region along the eastern North American coast is active all year, being a location with high baroclinicity due to the sea surface temperature gradients provided by the warm Gulf Stream. The surface temperature contrast does not give only conditions to genesis but also to the intensification of pre-existing cyclones and perturbations that come from continent - which may be generated on the lee side of Rockies. Grise et al. (2013) constructed a genesis density distribution using not the first track point of each cyclone but the location where 
228 storms exceeded the growth rate of 2 CVU per day, and they found a major genesis density along

229 the east coast of North America and less at the Rockies. The genesis region at the lee of the 230 northern Rockies and its consequent storm track density along the continent (e.g., Hoskins and 231 Hodges, 2002) does not appear in Figure 3 because these cyclones dissipate in the northeast 232 portion of the North American continent, outside the North Atlantic domain (Dacre and Gray, 233 2009). The genesis densities along the east Greenland coast are higher in Figure 3 than in some 234 previous studies selecting cyclones that last more than 48 h (e.g., Hoskins and Hodges, 2002; 235 Dacre and Gray, 2009; Grise et al., 2013). Trigo (2006) used the 24h threshold and also obtained 236 a more pronounced genesis density in Greenland.

\subsubsection{South Atlantic}

Figure 4 and Figure 5 show the cyclone track and genesis densities in the South Atlantic for the ERA5 and CFSR/CFSv2, computed for the whole period, as well as divided into austral 241 summer (DJF), and winter (JJA). The main South Atlantic storm track is defined by the high

242 concentration of systems [> 10 cyclones $\left(10^{-6}, \mathrm{~km}^{2}\right)^{-1}$ (month) $\left.{ }^{-1}\right]$ extending from west to east of 243 the domain, between $40^{\circ} \mathrm{S}$ and $55^{\circ} \mathrm{S}$. Furthermore, there is a secondary storm track [> 6 cyclones $244\left(10^{-6}, \mathrm{~km}^{2}\right)^{-1}$ (month) $\left.{ }^{-1}\right]$ that merges with the primary storm track, being considered a 245 subtropical branch. During the austral summer (DJF), the subtropical storm track spreads 246 northward, originating between $30^{\circ} \mathrm{S}$ and $35^{\circ} \mathrm{S}$, while during the winter this branch is 247 concentrated in $35^{\circ} \mathrm{S}$. The winter season variability in the South Atlantic storm track is linked to 248 changes in active genesis regions in South America, as is possible to see in the genesis density 249 spatial distribution (Figure 5). 
The genesis density for all period shows three main regions of active genesis [> 2 cyclones $251\left(10^{-6}, \mathrm{~km}^{2}\right)^{-1}$ (month) $\left.{ }^{-1}\right]$ : in Uruguay $\left(35^{\circ} \mathrm{S}, 60^{\circ} \mathrm{W}\right)$, Argentinean coast $\left(45^{\circ} \mathrm{S}, 65^{\circ} \mathrm{W}\right)$, and 252 Antarctic Peninsula $\left(65^{\circ} \mathrm{S}, 60^{\circ} \mathrm{W}\right)$. Secondary genesis regions exist in the Southeast Brazilian 253 coast $\left(27^{\circ} \mathrm{S}, 45^{\circ} \mathrm{W}\right)$, and southeast portion of South Atlantic (centered at $45^{\circ} \mathrm{S}, 10^{\circ} \mathrm{W}$ ). The former 254 is only pronounced during the austral summer, while the last has more genesis during the winter 255 (e.g., Gramcianinov et al., 2019). In South America, the genesis regions at Uruguay are more 256 active during JJA, while the Argentina's genesis region is more active in DJF. However, the 257 genesis region in Argentina presents a high density of genesis during all year [> 5 cyclones $\left(10^{-6}\right.$, $\left.258 \mathrm{~km}^{2}\right)^{-1}(\text { month })^{-1}$. The genesis region in Southeast Brazilian coast and Southeast South Atlantic 259 are more active in CFSR/CFSv2 climatology [ $>2$ cyclones $\left(10^{-6}, \mathrm{~km}^{2}\right)^{-1}$ (month) $\left.{ }^{-1}\right]$ than in 260 ERA5.

261 The spatial distribution and seasonal variation presented in Figure 4 and Figure 5 are in 262 agreement with previous studies (e.g., Hoskins and Hodges, 2005; Reboita et al., 2010; 263 Gramcianinov et al., 2019). A more direct comparison can be made with results from 264 Gramcianinov et al. (2019) since the system duration and displacement threshold applied are the 265 same $(24 \mathrm{~h}$ and $1000 \mathrm{~km})$. They found a slightly more active genesis region in the Southeast 266 Brazilian coast in DJF. Also, the Uruguay genesis region is much more active in the present 267 work, with a genesis density almost $20 \%$ larger.

\subsection{Differences between ERA5 and CFSR/CFSv2 cyclones}

Table 1 shows the cyclone annual and seasonal mean frequencies computed for the entire

271 period (1979 to 2011). Such values were also computed for the split period linked to CFSR 272 (1979-March/2011) and CFSv2 (April/2011-2019) separately, to analyze the differences between 
273 datasets. In general, ERA5 produces more cyclones than CFSR/CFSv2, which is expected due to

274 the higher resolution of the former. The differences between the two datasets are smaller in the

275 North Atlantic than in the South Atlantic in all cases. In the North Atlantic, the differences in

276 cyclone numbers are between $0.4 \%$ and $4.4 \%$, being the lowest and largest differences detected

277 in MAM and JJA respectively. The period of JJA is the only season that CFSR/CFSv2 presents

278 more cyclones than ERA5. The differences between datasets for the South Atlantic vary from

$2796.3 \%$ to $2.3 \%$. The largest difference occurs in JJA, the most active cyclonic season. By choosing

280 ERA5 as the reference, the CFSv2 improves the cyclone representation in the South Atlantic 281 when compared to its antecessor, since there is a reduction of differences between CFSv2 and 282 ERA5 when compared to CFSR and ERA5. It is not possible to conclude the same for the North 283 Atlantic, which presents a small increase or decrease of differences depending on the season.

284 The spatial distribution and intensity differences between ERA5 and CFSR/CFSv2 are 285 presented in the following subsections. The results focus on the storm track active season in each 286 ocean basin: boreal winter (DJF) for the North Atlantic, and austral winter (JJA) for the South 287 Atlantic.

\subsubsection{Spatial distribution}

290 The winter genesis and track density differences between the two datasets are presented in 291 Figure 6 for the North Atlantic (DJF) and South Atlantic (JJA). The difference is computed as 292 CFSR/CFSv2 minus ERA5, so positive (negative) values indicate that the CFSR/CFSv2 has 293 more (less) genesis or tracks in a location. Areas with significant differences ( $\mathrm{p}$-value $<0.01)$ are 294 marked with a black dot. First, for the North Atlantic, the track density difference shows that 295 ERA5 have more storm tracks than CFSR/CFSv2. The track differences do not show any dipole 
296 patterns that would indicate shifts between storm tracks but, instead, the negative values are 297 distributed all over the main North Atlantic storm track paths from the eastern portion of the 298 eastern USA to Iceland and the UK. However, there are some local differences in genesis density 299 comparisons. The CFSR/CFSv2 presents a more concentrated genesis along the eastern coast of 300 North American, between $40^{\circ} \mathrm{N}$ and $55^{\circ} \mathrm{N}$, and offshore areas. This genesis difference along the 301 coast generates an eastward shift of the east of North Atlantic genesis region between the two 302 datasets. The CFSR/CFSv2 also presents an active genesis region closer to the $\mathrm{UK}\left(15^{\circ} \mathrm{W}\right)$ than 303 ERA5 $\left(25^{\circ} \mathrm{W}\right)$. Differences are larger in the South Atlantic, both in genesis and track densities. 304 The track density differences show that ERA5 presents a higher track density in most of the 305 domain, particularly where the South Atlantic storm track is typically found, between $40^{\circ} \mathrm{S}$ and $30655^{\circ} \mathrm{S}$, following the spiral pattern typical of the winter. Moreover, in the southwest of the domain, 307 in the Drake Passage $\left(55^{\circ} \mathrm{S}\right.$ and $\left.66^{\circ} \mathrm{S}\right)$, there is a pronounced difference associated with cyclones 308 that come from the South Pacific Ocean. The genesis density difference shows that the 309 cyclogenesis regions over Uruguay and Argentina are more active in ERA5, while CFSR/CFSv2 310 favors genesis in the oceanic portion off of South America Eastern coast and Southeast of South 311 Atlantic. The genesis region in the Antarctic Peninsula is more active in ERA5, which are 312 connected to more cyclonic perturbations coming from the South Pacific.

\subsubsection{Cyclone intensity and additional characteristics}

315 Some important cyclones characteristics are shown in Table 2 for ERA5, CFSR/CFSv2, 316 CFSv2 and CFSR, for both oceanic basins. First, the mean initial vorticity is calculated by the 317 filtered vorticity (T42) at the time of the genesis in each track. The CFSR/CFSv2 presents larger 318 initial vorticity than ERA5, in all periods considered. The difference is larger for the South 
Atlantic, where CFSR/CFSv2 cyclones are $10.4 \%$ more intense at the time of the genesis than cyclones in ERA5. For the North Atlantic cyclones, CFSR/CFSv2 present storms $6.4 \%$ more intense than ERA5. The cyclone propagation speed is similar between datasets, which is expected once it is mainly dictated by the large scale flow. As is possible to see, regarding cyclones' mean characteristics, the differences between ERA5 and CFSR/CFSv2 are small, and not significant due to the large variance. Analyzing CFSR and CFSv2 separately, the differences compared to ERA5 decrease in version 2. Despite the large standard deviation, the mean values indicate that ERA5 cyclones seem to live longer and move further than CFSR/CFSv2 ones. To investigate further the duration and displacement differences between the two datasets the histograms of those cyclones characteristics are presented in Figure 7. In fact, the lifetime and displacement distributions show that CFSR/CFSv2 presents a larger portion of small-distance and short-life cyclones when compared to ERA5.

The intensity distributions are shown in Figure 8 for both the North Atlantic (DJF) and South Atlantic (JJA) in two periods: from 1979 to 2019, and April/2011 to 2019, the last referring to CFSv2 solely. Figure 8 also shows the intensity distribution of the matched tracks between datasets. The percentage of matched tracks between ERA5 and CFSR/CFSv2 can be found in Table 3. The maximum 10-m wind speed distribution for all cyclones shows that the CFSR/CFSv2 presents more intense cyclones than ERA5, as its distribution is shifted to the right. The mean maximum surface winds and percentiles of the distributions are displayed in Table 4. CFSR/CFSv2 presents a higher mean and percentiles, and the differences between the datasets are larger for the South Atlantic than North Atlantic. Additionally, the CFSv2 has a broader distribution when compared to ERA5, although this is more evident in the North Atlantic. The same behavior was observed by Hodges et al. (2011) when they compared CFSR 
342 and ERA-Interim. The tendency of CFSR/CFSv2 to simulate more intense storms is reported by

343 previous studies (Hodges et al., 2011; Stopa and Cheung, 2014; Gramcianinov et al., 2020b). The

344 matching storms distribution reveals more about the dissimilarities between the datasets since it

345 compares the same storm simulated in each one. The intensity distribution of the matched tracks

346 is very similar to the distribution obtained with all tracks, due to the high correspondence

347 percentage between datasets (Table 3). Even for the matching cyclones distributions,

348 CFSR/CFSv2 cyclones are more intense than ERA5 ones, reinforcing its tendency to simulate

349 stronger storms. Analysing CFSR alone (not shown) does not change this behavior, but the 350 intensity distributions computed for CFSv2 and ERA5 between April/2011 and 2019, present a

351 slight increase in cyclones intensity in relation to the mean and past distribution. The distribution

352 computed for the end of the period is shifted to the right, and has a more pronounced tail to the 353 right side of maximum wind speed axis.

354

355

\section{Discussion}

The cyclone climatologies covering 41-years produced from ERA5 and CFSR/CFSv2 are in

357 good agreement with past studies for the North Atlantic (e.g., Hoskins and Hodges, 2002; Trigo,

358 2006; Dacre and Gray, 2009) and South Atlantic Oceans (e.g., Hoskins and Hodges, 2005;

359 Gramcianinov et al., 2019). Differences in genesis and track densities between the present and 360 past studies are expected, particularly due to the use of distinct cyclone tracking methods, 361 domains, and thresholds that define whether a cyclonic feature is a cyclone or not (Pinto et al., 362 2005). The climatologies presented in this work show a higher cyclone density than Hoskins and 363 Hodges (2002, 2005), Dacre and Gray (2009), and Grise et al. (2013), since these authors remove 364 from their climatology cyclones that live less than $48 \mathrm{~h}$, which represent a large portion of the 

375 into a cyclone.

376

377

378 work.

systems in this study (Figure 7). However, when compared to Trigo (2006) and Gramcianinov et al (2019), which also used the 24 hours as cyclone lifetime threshold, the densities presented in this work are comparable (Figures 2-5). Genesis density in regions such as Greenland, in the North Atlantic, and the southeastern Brazilian coast, in the South Atlantic, seem to be enhanced by the addition of short-lived cyclones included in the statistics. These regions are also highlighted when a smaller displacement threshold is applied (Figure 1). Crespo et al. (2020b) showed five genesis region in South America without the application of any displacement threshold, contrasting the three well-known cyclogenetic regions (Hoskins and Hodges, 2005; Reboita et al., 2010; Gramcianinov et al., 2019). The use of displacement threshold is necessary to avoid the inclusion of thermal and continental lows in the climatology, which may not develop

Another source of discrepancies between the present and previous studies is the use of 1hourly tracking, since most climatologies are constructed based on 6-hourly atmospheric fields. The improved time-resolution tracking can result in slight differences in genesis position, such as can be observed on the East South American coast. Despite the same tracking method and thresholds, this work present a higher genesis density in Uruguay and a smaller density in the Southeast Brazilian coast than Gramcianinov et al. (2019), which can be associated with the identification of cyclones at earlier lifecycle stages with the use of 1-hourly tracking, instead of 6-hourly. Gramcianinov et al. (2019) used an artificial orographic barrier to impose an Andes constraint to their tracking method, which could influence the genesis region position in their

Regarding the main differences between the two data sets, ERA5 presents $3.7 \%$ more cyclones than CFSR/CFSv2 (45.2 cyclones per year), which can be related to the higher 
388 resolution of the former. The higher amount of cyclones in the ERA5 impacts the spatial 389 distribution differences both in the North Atlantic and South Atlantic. The track density 390 difference shows a homogeneous distribution in the major part of both domains and does not 391 reveal a shift between the tracks of the two datasets. The direct relation between model 392 resolution and the number of detected cyclones are indicated in many studies (e.g., Bengtsson et 393 al., 2006). The impact of resolution is affected by the orography representation and small-scale 394 processes important to genesis and growth. Therefore, the T42 filtering before the identification 395 process and tracking does not completely exclude the effects of the resolution on the 396 representation of cyclones in ERA5.

397 Cyclogenesis density differences show that CFSR/CFSv2 favors genesis off coast and above 398 the ocean sector, which induce a bias in genesis region along East of the North American coast 399 and Southwest of South American coast when compared to ERA5. This meridional shift in 400 genesis regions may also be related to resolution, once the best representation of orography, land 401 contrast and sea surface temperature can lead to early cyclone detection (e.g., Bengtsson et al., 402 2006) in the ERA5. However, the differences in genesis densities are evidence of differences in 403 the track lengths between the two datasets. ERA5 presents cyclones that lived longer and travel 404 further than CFSR/CFSv2 (Figure 7), which can be addressed to the inconsistency between 405 forecast and analysis sequential time-steps. Abrupt changes in atmospheric patterns between the 406 forecast and analysis time-step can interrupt a track, breaking a unique cyclone track into two. 407 This continuity issue in CFSR/CFSv2 influences its genesis density, and also its stronger initial 408 vorticity, since a broken track leads to a new track that starts in a more mature stage of the 409 cyclone. 
Cyclone annual mean and mean characteristics, such as displacement speed and initial 411 vorticity are similar between the two datasets, and their differences are less than 1 standard

412 deviation. Moreover, the track correspondence between the two datasets is high, being higher 413 than $90 \%$ to the whole period. In Hodges et al. (2011), the differences between more recent 414 datasets, ERA-Interim and CFSR, were smaller when compared to other older and coarser 415 resolution reanalysis. Both ERA5 and CFSR/CFSv2 are considered to be high-resolution global 416 products, and state of the art for analysis and reanalysis methodology.

417 The most pronounced difference is in the intensity distribution, which shows more intense 418 cyclones in CFSR/CFSv2 than in ERA5. The CFS family present a tendency to represent more 419 intense cyclones, winds and, consequently waves, as reported by several works (e.g., Hodges et 420 al., 2011; Stopa and Cheung, 2014; Gramcianinov et al., 2020b). There are no significant 421 difference between ERA5 and CFSR/CFSv2 when mean maximum wind speed is considered, 422 but the differences increase in the higher percentiles of the distributions (Table 4). The 10-m 423 wind components are diagnostic variables, and their computation depends on the different 424 boundary layers models component of each dataset. Even so, these parameters are widely used in 425 oceanography and ocean engineering studies and the evaluation of cyclone intensity by these 426 fields is of great value.

427 This study shows that the differences between ERA5 and CFSR/CFSv2 are larger for the 428 South Atlantic than North Atlantic. Other comparison studies found the same behavior (e.g., 429 Hodges et al., 2003; 2011; Stoppa and Cheung, 2004). However, there is a decrease of 430 discrepancies between ERA5 and the more recent CFSv2 when compared to CFSR, particularly 431 in the South Atlantic Ocean. The decrease in differences between datasets in recent years reflects 
432 the improvement of the models and increase in data availability as discussed by Hodges et al. 433 (2010).

434 The storm tracks for ERA5 and CFSR/CFSv2 used to produce the climatologies presented in 435 this work are available in ftp://masterftp.iag.usp.br/EXWAV. The provided product consists of 436 the set of monthly tracks files that contain the positional information of cyclones.

\section{Conclusions}

This study has evaluated and compared the cyclone climatologies for ERA5 and

440 CFSR/CFSv2 at middle and high latitudes. First, the performance of 1-hourly ERA5 and

441 CFSR/CFSv2 tracking in reproducing the Atlantic storm tracks was analyzed regarding the past

442 literature. Then, the two climatologies were compared to access the main differences between 443 them regarding the basics of storm track characteristics.

444 The storm tracks are in good agreement with past studies, both to North Atlantic (e.g., 445 Hoskins and Hodges, 2002; Trigo, 2006; Dacre and Gray, 2009; Grise et al., 2013), and South 446 Atlantic Oceans (e.g., Gan and Rao, 1991; Mendes et al., 2010; Reboita et al., 2010; 447 Gramcianinov et al., 2019; Crespo et al., 2020b). The main North Atlantic and South Atlantic 448 storm track characteristics, such as the spiral pattern poleward, seasonal variability, and 449 latitudinal range are represented, as well as the well-known genesis regions within these ocean 450 basins. The use of hourly fields brought benefits to the tracking, particularly in areas with 451 complex terrains, such as the lee of Andes Cordillera in the South America, and East of 452 Greenland in the North Atlantic.

453 Differences between datasets showed that ERA5 has 3.7\% more cyclones than CFSR/CFSv2, 454 which can be related to the finer resolution (e.g., Bengtsson et al., 2006). However, cyclone 
455 annual mean and mean characteristics (e.g., displacement speed) are similar between the two 456 datasets, and $90 \%$ of the tracks correspond between them. An important difference between

457 ERA5 and CFSR/CFSv2 are the shifts in genesis density along the eastern coast, both in North 458 and South America, which can be an indication of resolution impact in cyclone development in 459 regions with complex orography, and temperature gradient. Furthermore, continuity issues in 460 CFSR/CFSv2 due to jumps that might occur where forecast time-steps change to analysis time461 steps can lead to broken tracks, and thus, differences between the two datasets, particularly 462 related to genesis statistics and cyclone duration lifecycle.

463 Other relevant differences between ERA5 and CFSR/CFSv2 are the intensity distributions, 464 particularly in the higher percentile of maximum 10-m wind speed. The CFSR/CFSv2 dataset 465 presents more intense cyclones than ERA5 and this behavior persists even when CFSR and 466 CFSv2 were evaluated separately. Other studies have already reported the ability of CFSR 467 (Hodges et al., 2011; Stopa and Cheung, 2014) and CFSv2 (e.g., Gramcianinov et al., 2020b) to 468 represent more extreme wind speed values. It is remarkable that in most of the analyses 469 performed in this work, the differences between datasets decrease when CFSv2 period is 470 analyzed separately, revealing rather a bias correction in the operational version of CFS or an 471 increase of available data and improvement of data assimilation method. In fact, the 472 discrepancies reduction is more pronounced in the South Atlantic, which reinforces the role of 473 data assimilation process in the convergence of the two datasets (e.g., Hodges et al., 2011; Stopa 474 and Cheung, 2014).

475

476 Acknowledgments 
This work is part of the project "Extreme wind and wave modeling and statistics in the 478 Atlantic Ocean" (EXWAV) funded by the Portuguese Foundation for Science and Technology 479 (Fundação para a Ciência e Tecnologia - FCT) under contract PTDC/EAM-OCE/31325/2017 480 RD0504, and by the São Paulo Research Foundation (FAPESP) grant \#2018/08057-5. C.B.G. 481 holds a FAPESP post-doc scholarship grant \#2020/01416-0. The authors would like to 482 acknowledge the NCEP and ECMWF for providing the atmospheric and wave data for the study. 483 The ERA5 products were generated using Copernicus Climate Change Service Information 484 [2019]. This study used the high-performance computing resources of the SDumont 485 supercomputer (http://sdumont.lncc.br), which is provided by the National Laboratory for 486 Scientific Computing (LNCC/MCTI, Brazil).

487

488

\section{References}

489

Bakhtyar, R., Orton, P.M., Marsooli, R., Miller, J.K., 2018. Rapid wave modeling of severe 490 historical extratropical cyclones off the Northeastern United States. Ocean Eng. 159, 315491 332. https://doi.org/10.1016/j.oceaneng.2018.04.037

492 Belmonte Rivas, M., Stoffelen, A., 2019. Characterizing ERA-Interim and ERA5 surface wind 493 biases using ASCAT. Ocean Sci. 15, 831-852. https://doi.org/10.5194/os-15-831-2019

494 Bengtsson, L., Hodges, K.I., Keenlyside, N., 2009. Will extratropical storms intensify in a 495 warmer climate? J. Clim. 22, 2276-2301. https://doi.org/10.1175/2008JCLI2678.1

496 Bengtsson, L., Hodges, K.I., Roeckner, E., 2006. Storm tracks and climate change. J. Clim. 19, 497 3518-3543. https://doi.org/10.1175/JCLI3815.1 
Booth, J.F., Rieder, H.E., Kushnir, Y., 2016. Comparing hurricane and extratropical storm surge for the Mid-Atlantic and Northeast Coast of the United States for 1979-2013. Environ. Res. Lett. 11(9). 10.1088/1748-9326/11/9/094004

Campos, R.M., Guedes Soares, C., 2016. Comparison and Assessment of Three Wave Hindcasts in the North Atlantic Ocean. J. Oper. Oceanogr. 9(1):26-44. https://doi.org/10.1080/1755876X.2016.1200249

Campos, R.M., Guedes Soares, C., 2017. Assessment of Three Wind Reanalysis in the North $\begin{array}{lllll}\text { Atlantic Ocean. } & \text { J. Oper. }\end{array}$ https://doi.org/10.1080/1755876X.2016.1253328

Campos, R.M., Alves, J.H.G.M., Guedes Soares, C., Guimaraes, L.G., Parente, C.E., 2018. Extreme wind-wave modeling and analysis in the South Atlantic Ocean. Ocean Model. 124, 75-93. https://doi.org/10.1016/j.ocemod.2018.02.002

Campos, R.M., Guedes Soares, C., Alves, J.H.G.M., Parente, C.E., Guimaraes, L.G., 2019. Regional long-term extreme wave analysis using hindcast data from the South Atlantic Ocean. Ocean Eng. 179, 202-212. https://doi.org/10.1016/j.oceaneng.2019.03.023

Chelton, D. B., Schlax, M. G., Freilich, M. H., Milliff, R. F., 2004. Satellite measurements reveal persistent small-scale features in ocean winds. Science 303, 978-983, https://doi.org/10.1126/science.1091901

Colle, B.A., Rojowsky, K., Buonaito, F., 2010. New York city storm surges: Climatology and an analysis of the wind and cyclone evolution. J. Appl. Meteorol. Climatol. 49(1): 85-100. 10.1175/2009JAMC2189.1 
519 Copernicus Climate Change Service (C3S) 2017. ERA5: Fifth generation of ECMWF 520 atmospheric reanalyses of the global climate. Copernicus Climate Change Service Climate 521 Data Store (CDS), July, 2019.

522 Crespo, N.M.; da Rocha, R.P.; De Jesus, E.M., 2020a. Cyclones density and characteristics in 523 different reanalyses dataset over South America. In: EGU General Assembly 2020, Online, 45248 May 2020, EGU2020-11316. https://doi.org/10.5194/egusphere-egu2020-11316

525 Crespo, N.M., da Rocha, R.P., Sprenger, M., Wernli, H., 2020b. A Potential Vorticity 526 Perspective on Cyclogenesis over Center-Eastern South America. Int. J. Climatol. 1-16. 527 https://doi.org/10.1002/joc.6644

528 Dacre, H.F., Gray, S.L., 2009. The spatial distribution and evolution characteristics of North 529 Atlantic cyclones. Mon. Weather Rev. 137, 99-115. $530 \quad$ https://doi.org/10.1175/2008MWR2491.1

531 Dacre, H.F., Hawcroft, M.K., Stringer, M.A., Hodges, K.I., 2012. An extratropical cyclone atlas 532 a tool for illustrating cyclone structure and evolution characteristics. Bull. Am. Meteorol. Soc. 93, 1497-1502. https://doi.org/10.1175/BAMS-D-11-00164.1

534 Evans, J. L., Braun, A., 2012. A Climatology of Subtropical Cyclones in the South Atlantic. J. 535 Climate 25, 7328-7340, https://doi.org/10.1175/JCLI-D-11-00212.1.

536 Gan, M.A., Rao, V.B., 1991. Surface Cyclogenesis over South America. Mon. Weather Rev. 537 119, 1293-1302. https://doi.org/10.1175/1520-0493(1991)119<1293:SCOSA>2.0.CO;2

538 Gozzo, L.F., da Rocha, R.P., Reboita, M.S., Sugahara, S., 2014. Subtropical cyclones over the 539 southwestern South Atlantic: Climatological aspects and case study. J. Clim. 27, 8543-8562. $540 \quad$ https://doi.org/10.1175/JCLI-D-14-00149.1 
541 Gramcianinov, C.B., Campos, R.M., Guedes Soares, C., Camargo, R., 2020a. Extreme waves 542 generated by cyclonic winds in the western portion of the South Atlantic Ocean. Ocean Eng. 543 213: 107745. https://doi.org/10.1016/j.oceaneng.2020.107745

544 Gramcianinov, Campos, R.M., Guedes Soares, C., Camargo, R., 2020b. Comparison between 545 ERA5 and CFS datasets of extratropical cyclones associated with extreme wave events in the 546 Atlantic Ocean. Proceedings of the ASME 2020 29th International Conference on Offshore 547 Mechanics and Arctic Engineering, Online, 3-7 August, 2020, ASME.

548 Gramcianinov, C.B., Hodges, K.I., Camargo, R., 2019. The properties and genesis environments 549 of South Atlantic cyclones. Clim. Dyn. 53, 4115-4140. https://doi.org/10.1007/s00382-01904778-1

551 Grise, K.M., Son, S.W., Gyakum, J.R., 2013. Intraseasonal and interannual variability in north 552 american storm tracks and its relationship to equatorial pacific variability. Mon. Weather Rev. 553 141, 3610-3625. https://doi.org/10.1175/MWR-D-12-00322.1

554 Guishard, M.P., Evans, J.L., Hart, R.E., 2009. Atlantic subtropical storms. Part II: Climatology. 555 556 J. Clim. 22, 3574 - 3594. https://doi.org/10.1175/2008JCLI2346.1

Hersbach, H., Dee, D., 2016. ERA5 reanalysis is in production, ECMWF Newsletter 147, ECMWF, Reading, UK, 2016.

Hersbach, H., Bell, B., Berrisford, P., Horányi, A., Sabater, J.M., Nicolas, J., Radu, R., Schepers, D., Simmons, A., Soci, C., Dee, D., 2018. Global reanalysis: goodbye ERA-Interim, hello 560 ERA5. ECMWF Newsl. 17-24. https://doi.org/10.21957/vf291hehd7

561 Hodges, K.I., 1994. A General Method for Tracking Analysis and Its Application to 562 Meteorological Data. Mon. Weather Rev. 122, 2573-2586. https://doi.org/10.1175/1520563 0493(1994)122<2573:AGMFTA>2.0.CO;2 
572

Hodges, K.I., 1995. Feature Tracking on the Unit Sphere. Mon. Weather Rev. 123, 3458-3465. https://doi.org/10.1175/1520-0493(1995)123<3458:FTOTUS>2.0.CO;2

Hodges, K.I., 1996. Spherical Nonparametric Estimators Applied to the UGAMP Model Integration for AMIP. Mon. Weather Rev. 124, 2914-2932. https://doi.org/10.1175/15200493(1996)124<2914:SNEATT>2.0.CO;2

Hodges, K.I., 1999. Adaptive constraints for feature tracking. Mon. Weather. Rev., 127, 13621373. https://doi.org/10.1175/1520-0493(1999)127<1362:ACFFT>2.0.CO;2

Hodges, K.I., 2008: Confidence intervals and significance tests for spherical data derived from feature tracking. Mon. Weather Rev., 136, 1758-1777. https://doi.org/10.1175/2007MWR2299.1

Hodges, K.I., Hoskins, B.J., Boyle, J., Thorncroft, C., 2003. A Comparison of Recent Reanalysis Datasets Using Objective Feature Tracking: Storm Tracks and Tropical Easterly Waves. Mon. Weather Rev. 131, 2012-2037. https://doi.org/10.1175/15200493(2003)131<2012:ACORRD>2.0.CO;2

Hodges, K.I., Lee, R.W., Bengtsson, L., 2011. A comparison of extratropical cyclones in recent reanalyses ERA-Interim, NASA MERRA, NCEP CFSR, and JRA-25. J Clim 24:4888-4906. https://doi.org/10.1175/2011JCLI4097.1

Hoskins, B.J., Hodges, K.I., 2002. New Perspectives on the Northern Hemisphere Winter Storm Tracks. J. Atmos. Sci. 59, 1041-1061. https://doi.org/10.1175/15200469(2002)059<1041:NPOTNH>2.0.CO;2

Hoskins, B.J., Hodges, K.I., 2005. A New Perspective on Southern Hemisphere Storm Tracks. J. Clim. 18, 4108-4129. https://doi.org/10.1175/JCLI3570.1 
Jones, D.A., Simmonds, I., 1993. A climatology of Southern Hemisphere extratropical cyclones. Climate Dyn. 9, 131-145. https://doi.org/10.1007/BF00209750

Kalnay, E., Kanamitsu, M., Kistler, R., Collins, W., Deaven, D., Gandin, L., Iredell, M., Saha, S., White, G., Woollen, J., Zhu, Y., Chelliah, M., Ebisuzaki, W., Higgins, W., Janowiak, J., Mo, K.C., Ropelewski, C., Wang, J., Leetmaa, A., Reynolds, R., Jenne, R., Joseph, D., 1996. The NCEP/NCAR 40-Year Reanalysis Project. Bull. Amer. Meteor. Soc., 77, 437-472. https://doi.org/10.1175/1520-0477(1996)077<0437:TNYRP>2.0.CO;2

Kumar, V.S., Mandal, S., Kumar, K.A., 2003. Estimation of wind speed and wave height during cyclones. Ocean Eng. 30, 2239-2253. https://doi.org/10.1016/S0029-8018(03)00076-3

Mattioli, M., De Masi, G., Drago, M., 2019. Evaluating extreme cyclonic sea states. Ocean Eng. 194, 106639. https://doi.org/10.1016/j.oceaneng.2019.106639

Mendes, D., Souza, E.P., Marengo, J.A., Mendes, M.C.D., 2010. Climatology of extratropical cyclones over the South American-southern oceans sector. Theor. Appl. Climatol. 100, 239250. https://doi.org/10.1007/s00704-009-0161-6

Murray, R.J., Simmonds, I., 1991a. A numerical scheme for tracking cyclone centres from digital data Part I: development and operation of the scheme. Aust. Meteorol. Mag. 39, 155-166.

Murray, R.J., Simmonds, I., 1991b. A numerical scheme for tracking cyclone centres from digital data. Part II: application to January and July general circulation model simulations. Aust. Meteorol. Mag. 39, 155-166.

Olauson, J., 2018. ERA5: The new champion of wind power modelling? Renew. Energy 126, 322-331. https://doi.org/10.1016/j.renene.2018.03.056

Onogi, K., Tsutsui, J., Koide, H., Sakamoto, M., Kobayashi, S., Hatsushika, H., Matsumoto, T., Yamazaki, N., Kamahori, H., Takahashi, K., Kadokura, S., Wada, K., Kato, K., Oyama, R., 
Ose, T., Mannoji, N., Taira, R., 2007. The JRA-25 Reanalysis. J. Meteorol. Soc. Japan. Ser. II 85, 369-432. https://doi.org/10.2151/jmsj.85.369

Parker, W.S., 2016. Reanalyses and observations: What's the Difference? Bull. Am. Meteorol. Soc. 97, 1565-1572. https://doi.org/10.1175/BAMS-D-14-00226.1

Pinto, J.G., Spangehl, T., Ulbrich, U., Speth, P., 2005. Sensitivities of a cyclone detection and tracking algorithm: Individual tracks and climatology. Meteorol. Zeitschrift 14, 823-838. https://doi.org/10.1127/0941-2948/2005/0068

Ponce De León, S., Guedes Soares, C., 2012. Distribution of winter wave spectral peaks in the seas around Norway. Ocean Eng. 50, 63-71. https://doi.org/10.1016/j.oceaneng.2012.05.005

Raible, C.C., Della-Marta, P.M., Schwierz, C., Wernli, H., Blender, R., 2008. Northern Hemisphere Extratropical Cyclones: A Comparison of Detection and Tracking Methods and Different Reanalyses. Mon. Weather Rev. 136, 880-897. https://doi.org/10.1175/2007MWR2143.1

Reboita, M.S., da Rocha, R.P., Ambrizzi, T., Sugahara, S., 2010. South Atlantic Ocean cyclogenesis climatology simulated by regional climate model (RegCM3). Clim. Dyn. 35, 1331-1347. https://doi.org/10.1007/s00382-009-0668-7

Reboita, M.S., da Rocha, R.P., de Souza, M.R., Llopart, M., 2018. Extratropical cyclones over the southwestern South Atlantic Ocean: HadGEM2-ES and RegCM4 projections. Int. J. Climatol. 38, 2866-2879. https://doi.org/10.1002/joc.5468

Rienecker, M.M., Suarez, M.J., Gelaro, R., Todling, R., Bacmeister, J., Liu, E., Bosilovich, M.G., Schubert, S.D., Takacs, L., Kim, G., Bloom, S., Chen, J., Collins, D., Conaty, A., da Silva, A., Gu, W., Joiner, J., Koster, R.D., Lucchesi, R., Molod, A., Owens, T., Pawson, S., Pegion, P., Redder, C.R., Reichle, R., Robertson, F.R., Ruddick, A.G., Sienkiewicz, M.. 
Woollen, J., 2011. MERRA: NASA's Modern-Era Retrospective Analysis for Research and Applications. J. Climate, 24, 3624-3648

Saha, S., Moorthi, S., Pan, H., Wu, X., Wang, J., Nadiga, S., Tripp, P., Kistler, R., Woollen, J., Behringer, D., Liu, H., Stokes, D., Grumbine, R., Gayno, G., Wang, J., Hou, Y., Chuang, H., Juang, H.H., Sela, J., Iredell, M., Treadon, R., Kleist, D., Delst, P. Van, Keyser, D., Derber, J., Ek, M., Meng, J., Wei, H., Yang, R., Lord, S., Dool, H. van den, Kumar, A., Wang, W., Long, C., Chelliah, M., Xue, Y., Huang, B., Schemm, J., Ebisuzaki, W., Lin, R., Xie, P., Chen, M., Zhou, S., Higgins, W., Zou, C., Liu, Q., Chen, Y., Han, Y.,Cucurull, L., Reynolds, R.W., Rutledge, G., Goldberg, M., 2010. The NCEP Climate Forecast System Reanalysis. Bull. Amer. Meteor. Soc., 91, 1015-1058. https://doi.org/10.1175/2010BAMS3001.1

Saha, S., S. Moorthi, S., Wu, X., Wang, J., Nadiga, S., Tripp, P, Behringer, D., Hou, Y., Chuang, H., Iredell, M., Ek, M., Meng, J., Yang, R., Mendez, M.P., Dool, H. van den, Zhang, Q., Wang, W., Chen, M., Becker, E., 2014. The NCEP Climate Forecast System Version 2. J. Climate, 27, 2185-2208. https://doi.org/10.1175/JCLI-D-12-00823.1

Sebastian, M., Behera, M.R., Murty P.L.N., 2019. Storm surge hydrodynamics at a concave coast due to varying approach angles of cyclone. Ocean. Eng. 191. https://doi.org/10.1016/j.oceaneng.2019.106437

Simmonds, I., Keay, K., 2000. Mean southern hemisphere extratropical cyclone behavior in the 40-year NCEP-NCAR reanalysis. J. Clim. 13, 873-885. https://doi.org/10.1175/15200442(2000)013<0873:MSHECB>2.0.CO;2

Simmonds, I., Keay, K., 2000. Mean southern hemisphere extratropical cyclone behavior in the 40-year NCEP-NCAR reanalysis. J. Clim. 13, 873-885. https://doi.org/10.1175/15200442(2000)013<0873:MSHECB>2.0.CO;2 
655 Simmons, A., Uppala, S., Dee, D., Kobayashi, S., 2007. ERA-Interim: New ECMWF reanalysis 656 products from 1989 onwards. ECMWF Newsletter 110, ECMWF, Reading, UK, 25-35.

657 Sinclair, M.R., 1994. An objective cyclone climatology for the Southern Hemisphere. Mon. Wea. 658 Rev., 122, 2239-2256.

659 Sinclair, M.R., 1997. Objective Identification of Cyclones and Their Circulation Intensity, and 660 Climatology. Weather Forecast. 12, 595-612. https://doi.org/10.1175/1520661 0434(1997)012<0595:OIOCAT>2.0.CO;2

662 Stopa, J.E., Cheung, K.F., 2014. Intercomparison of wind and wave data from the ECMWF 663 Reanalysis Interim and the NCEP Climate Forecast System Reanalysis. Ocean Model. 75, $664 \quad 65-83$.

665 Trigo, I.F., 2006. Climatology and interannual variability of storm-tracks in the Euro-Atlantic 666 sector: A comparison between ERA-40 and NCEP/NCAR reanalyses. Clim. Dyn. 26, 127667 143. https://doi.org/10.1007/s00382-005-0065-9

668 Vettor, R., Guedes Soares, C., 2016. Rough weather avoidance effect on the wave climate 669 experienced by oceangoing vessels. Appl. Ocean Res. 59, 606-615. 670 https://doi.org/10.1016/j.apor.2016.06.004

671 Vettor, R., Guedes Soares, C., 2017. Characterization of the expected weather conditions in the 672 main European coastal traffic routes. Ocean Eng. 140, 244-257. 673 https://doi.org/10.1016/j.oceaneng.2017.05.027 
676 Table 1. Mean number of cyclones tracked in ERA5 and CFSR/CFSv2 between 1979 and 2019, annual 677 and seasonal mean. The mean are also computed for CFSR (1979-March/2011) and CFSv2 (April/2011678 2019) alone. All cyclones that pass within the extratropical latitudes of the South Atlantic (SA; $85^{\circ} \mathrm{S}-25^{\circ} \mathrm{S}$, $\left.67975^{\circ} \mathrm{W}-20^{\circ} \mathrm{E}\right)$ and North Atlantic (NA; $\left.85^{\circ} \mathrm{N}-25^{\circ} \mathrm{N}, 65^{\circ} \mathrm{W}-0^{\circ} \mathrm{E}\right)$ Oceans were considered.

\begin{tabular}{ccccccc}
\hline & & & & $\mathbf{1 9 7 9 - 2 0 1 9}$ & & \\
& & Annual & DJF & MAM & JJA & SON \\
\hline \hline NA & ERA5 & $551.0 \pm 23.6$ & $155.8 \pm 9.7$ & $140.9 \pm 10.6$ & $117.5 \pm 8.3$ & $136.7 \pm 9.1$ \\
& CFSR/CFSv2 & $538.7 \pm 21.2$ & $152.9 \pm 8.1$ & $135.2 \pm 11.3$ & $118.0 \pm 7.9$ & $132.7 \pm 8.8$ \\
\hline SA & ERA5 & $730.9 \pm 21.4$ & $158.2 \pm 10.0$ & $184.8 \pm 11.5$ & $201.9 \pm 11.7$ & $186.0 \pm 9.9$ \\
& CFSR/CFSv2 & $698.0 \pm 19.7$ & $154.2 \pm 9.6$ & $177.1 \pm 10.6$ & $189.3 \pm 10.2$ & $177.4 \pm 10.0$ \\
\hline & & & & $\mathbf{1 9 7 9 - 2 0 1 1}$ & & \\
& & Annual & DJF & MAM & JJA & SON \\
\hline \hline NA & ERA5 & $537.8 \pm 72.5$ & $154.4 \pm 14.8$ & $137.7 \pm 16.4$ & $117.5 \pm 8.7$ & $135.8 \pm 8.9$ \\
& CFSR & $525.2 \pm 69.9$ & $151.7 \pm 12.9$ & $131.7 \pm 16.9$ & $117.5 \pm 7.3$ & $131.8 \pm 8.4$ \\
\hline SA & ERA5 & $709.2 \pm 100.4$ & $155.0 \pm 14.1$ & $180.9 \pm 24.5$ & $200.3 \pm 11.8$ & $184.6 \pm 10.6$ \\
& CFSR & $678.7 \pm 97.5$ & $151.5 \pm 14.4$ & $174.3 \pm 24.3$ & $187.8 \pm 10.1$ & $176.2 \pm 10.4$ \\
\hline & & & & $\mathbf{2 0 1 1 - 2 0 1 9}$ & & \\
& & Annual & DJF & MAM & JJA & SON \\
\hline \hline NA & ERA5 & $538.1 \pm 52.9$ & $143.8 \pm 36.6$ & $137.2 \pm 18.6$ & $117.6 \pm 7.0$ & $139.6 \pm 9.4$ \\
& CFSv2 & $528.6 \pm 54.0$ & $140.0 \pm 35.6$ & $133.1 \pm 16.6$ & $119.8 \pm 10.0$ & $135.7 \pm 10.0$ \\
SA & ERA5 & $729.3 \pm 57.9$ & $152.4 \pm 33.9$ & $178.4 \pm 22.3$ & $207.7 \pm 9.8$ & $190.8 \pm 5.1$ \\
& CFSv2 & $691.0 \pm 61.2$ & $147.1 \pm 30.9$ & $167.8 \pm 21.6$ & $194.6 \pm 9.5$ & $181.6 \pm 7.6$ \\
\hline
\end{tabular}


Table 2. Mean characteristics of cyclones for ERA5 and CFSR/CFSv2 (1979-2019), and computed for for CFSR (1979-March/2011) and CFSv2 (April/2011-2019) separately. Initial vorticity is the filtered relative vorticity at the time of genesis, and is scaled by -1 in South Atlantic. Displacement is computed using the first and the last track point. All cyclones that pass within the extratropical latitudes of the South Atlantic $\left(\mathrm{SA} ; 85^{\circ} \mathrm{S}-25^{\circ} \mathrm{S}, 75^{\circ} \mathrm{W}-20^{\circ} \mathrm{E}\right)$ and North Atlantic $\left(\mathrm{NA} ; 85^{\circ} \mathrm{N}-25^{\circ} \mathrm{N}, 65^{\circ} \mathrm{W}-0^{\circ} \mathrm{E}\right)$ Oceans were

692 considered.

\begin{tabular}{|c|c|c|c|c|c|}
\hline & & \multicolumn{4}{|c|}{1979 - 2019} \\
\hline & & Initial vorticity (CVU) & Lifetime (days) & Displacement (m) & Speed $\left(\mathrm{km} \mathrm{h}^{-1}\right)$ \\
\hline \multirow[t]{2}{*}{$\overline{\mathbf{N A}}$} & 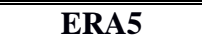 & $2.7 \pm 1.4$ & $4.4 \pm 3.0$ & $2928.5 \pm 1582.2$ & $9.6 \pm 4.7$ \\
\hline & CFSR/CFSv2 & $2.8 \pm 1.5$ & $4.0 \pm 2.6$ & $2767.8 \pm 1467.6$ & $9.8 \pm 4.6$ \\
\hline \multirow[t]{4}{*}{$\mathbf{S A}$} & ERA5 & $2.9 \pm 1.5$ & $3.9 \pm 2.6$ & $3712.0 \pm 2157.9$ & $13.2 \pm 5.3$ \\
\hline & CFSR/CFSv2 & $3.2 \pm 1.6$ & $3.3 \pm 2.1$ & $3228.3 \pm 1855.6$ & $13.3 \pm 5.3$ \\
\hline & & \multicolumn{4}{|c|}{1979 - 2011} \\
\hline & & Initial vorticity (CVU) & Lifetime (days) & Displacement (m) & Speed $\left(\mathbf{k m ~ h}^{-1}\right)$ \\
\hline \multirow[t]{2}{*}{ NA } & ERA5 & $2.7 \pm 1.4$ & $4.4 \pm 2.9$ & $2919.2 \pm 1569.4$ & $9.6 \pm 4.6$ \\
\hline & CFSR & $2.9 \pm 1.5$ & $4.0 \pm 2.6$ & $2750.6 \pm 1452.6$ & $9.8 \pm 4.6$ \\
\hline \multirow[t]{4}{*}{$\mathbf{S A}$} & ERA5 & $2.9 \pm 1.5$ & $3.9 \pm 2.6$ & $3688.0 \pm 2146.9$ & $13.2 \pm 5.3$ \\
\hline & CFSR & $3.3 \pm 1.6$ & $3.2 \pm 2.1$ & $3155.5 \pm 1799.8$ & $13.3 \pm 5.3$ \\
\hline & & \multicolumn{4}{|c|}{$2011-2019$} \\
\hline & & Initial vorticity (CVU) & Lifetime (days) & Displacement (m) & Speed $\left(\mathrm{km} \mathrm{h}^{-1}\right)$ \\
\hline \multirow[t]{2}{*}{$\mathbf{N A}$} & ERA5 & $2.7 \pm 1.5$ & $4.5 \pm 3.1$ & $2962.5 \pm 1628.0$ & $9.6 \pm 4.8$ \\
\hline & CFSv2 & $2.8 \pm 1.6$ & $4.1 \pm 2.7$ & $2830.7 \pm 1519.6$ & $9.8 \pm 4.7$ \\
\hline \multirow[t]{2}{*}{$\mathbf{S A}$} & ERA5 & $3.0 \pm 1.5$ & $4.0 \pm 2.7$ & $3797.7 \pm 2194.7$ & $13.3 \pm 5.4$ \\
\hline & CFSv2 & $3.2 \pm 1.6$ & $3.6 \pm 2.3$ & $3490.3 \pm 2022.5$ & $13.4 \pm 5.3$ \\
\hline
\end{tabular}

Table 3. Percentage of the number of matched tracks for ERA5 and CFSR/CFSv2 (1979-2019), CFSR

696 Atlantic (NA), and JJA for the South Atlantic (SA) Oceans.

1979 - 20191979 - 20112011 - 2019

\begin{tabular}{ccccc}
\hline \hline NA & ERA5 & $92.7 \%$ & $91.9 \%$ & $87.1 \%$ \\
& CFSR/CFSv2 & $96.0 \%$ & $94.9 \%$ & $91.1 \%$ \\
\hline SA & ERA5 & $93.1 \%$ & $91.8 \%$ & $89.2 \%$ \\
& CFSR/CFSv2 & $96.5 \%$ & $95.4 \%$ & $91.8 \%$ \\
\hline
\end{tabular}


698 Table 4. Mean maximum 10-m wind speed $\left(\mathrm{m} \mathrm{s}^{-1}\right)$ and percentiles of cyclones for ERA5 and 699 CFSR/CFSv2 (1979-2019) in DJF for the North Atlantic (NA), and JJA for the South Atlantic (SA)

700 Oceans. Matched cyclones are identical storms find in both datasets.

\begin{tabular}{|c|c|c|c|c|c|c|c|c|c|}
\hline & & \multicolumn{4}{|c|}{ ERA5 } & \multicolumn{4}{|c|}{ CFSR/CFSv2 } \\
\hline & & mean & $50 \%$ & $90 \%$ & $95 \%$ & mean & $\mathbf{5 0 \%}$ & $90 \%$ & $95 \%$ \\
\hline \multirow[t]{2}{*}{ NA } & all & $21.4 \pm 5.1$ & 21.1 & 28.2 & 30.1 & $23.9 \pm 6.4$ & 23.7 & 32.5 & 35.0 \\
\hline & matched & $21.5 \pm 5.1$ & 21.2 & 28.3 & 30.2 & $24.0 \pm 6.4$ & 23.8 & 32.6 & 35.0 \\
\hline \multirow[t]{2}{*}{$\mathbf{S A}$} & all & $21.2 \pm 4.8$ & 21.0 & 27.3 & 29.3 & $23.4 \pm 4.8$ & 23.3 & 30.2 & 32.1 \\
\hline & matched & $21.2 \pm 4.8$ & 21.0 & 27.4 & 29.3 & $23.4 \pm 5.3$ & 23.4 & 30.2 & 32.2 \\
\hline
\end{tabular}

701 


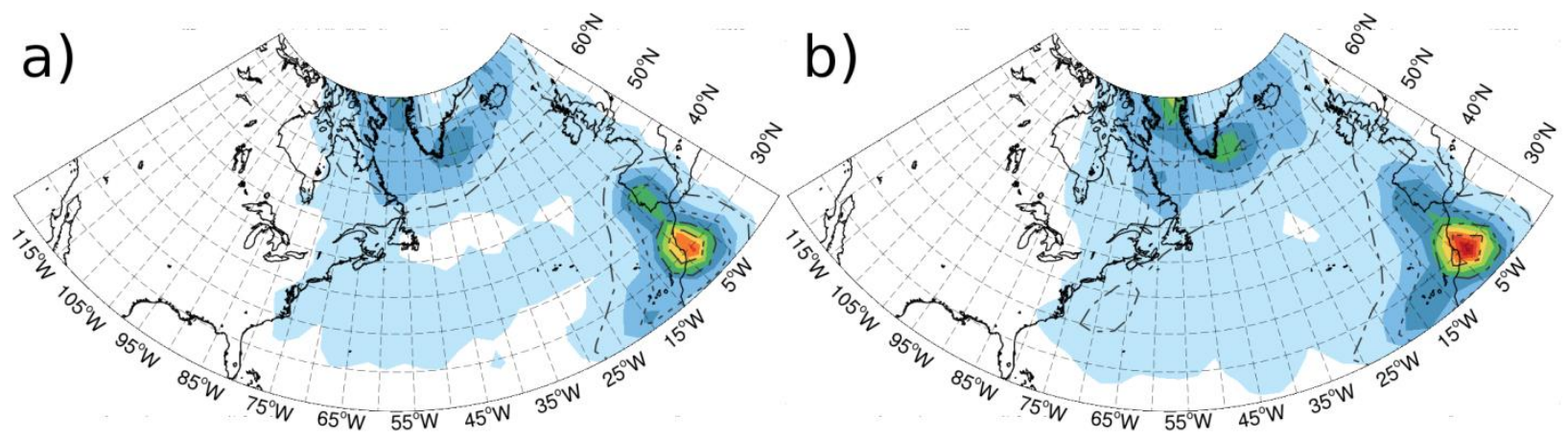

C)

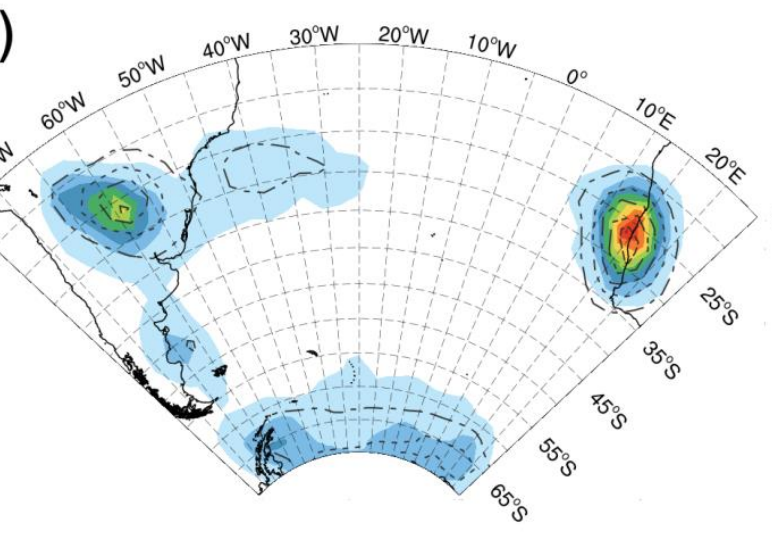

d)
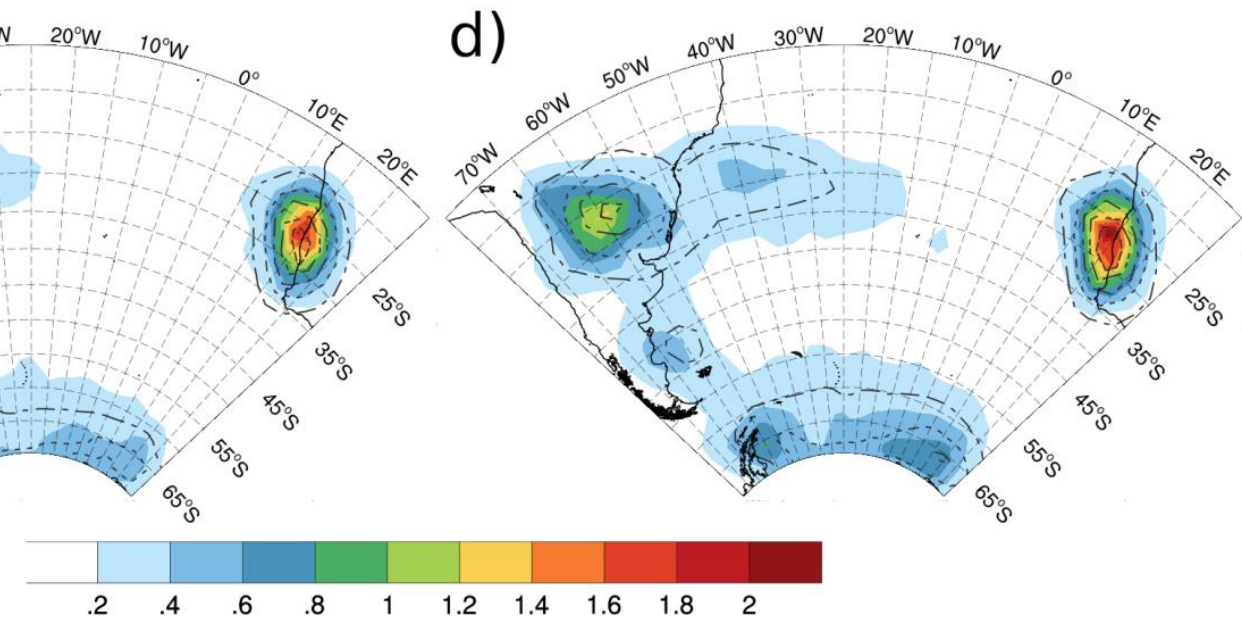

Figure 1. Genesis (shaded) and track (contour) densities computed for cyclones that last at least 24 hour and travel less than $1000 \mathrm{~km}$ for the (a) North Atlantic in ERA5 and (b) CFSR/CFSv2, and (c) South Atlantic in ERA5 and (d) CFSR/CFSv2. The density unit is cyclones/track per month per area, where the unit area is equivalent to a $5^{\circ}$ spherical cap $\left(10^{6} \mathrm{~km}^{2}\right)$. The track density contour are with contour interval 1 track per month per area, and the densities are calculated for 1979-2019. 

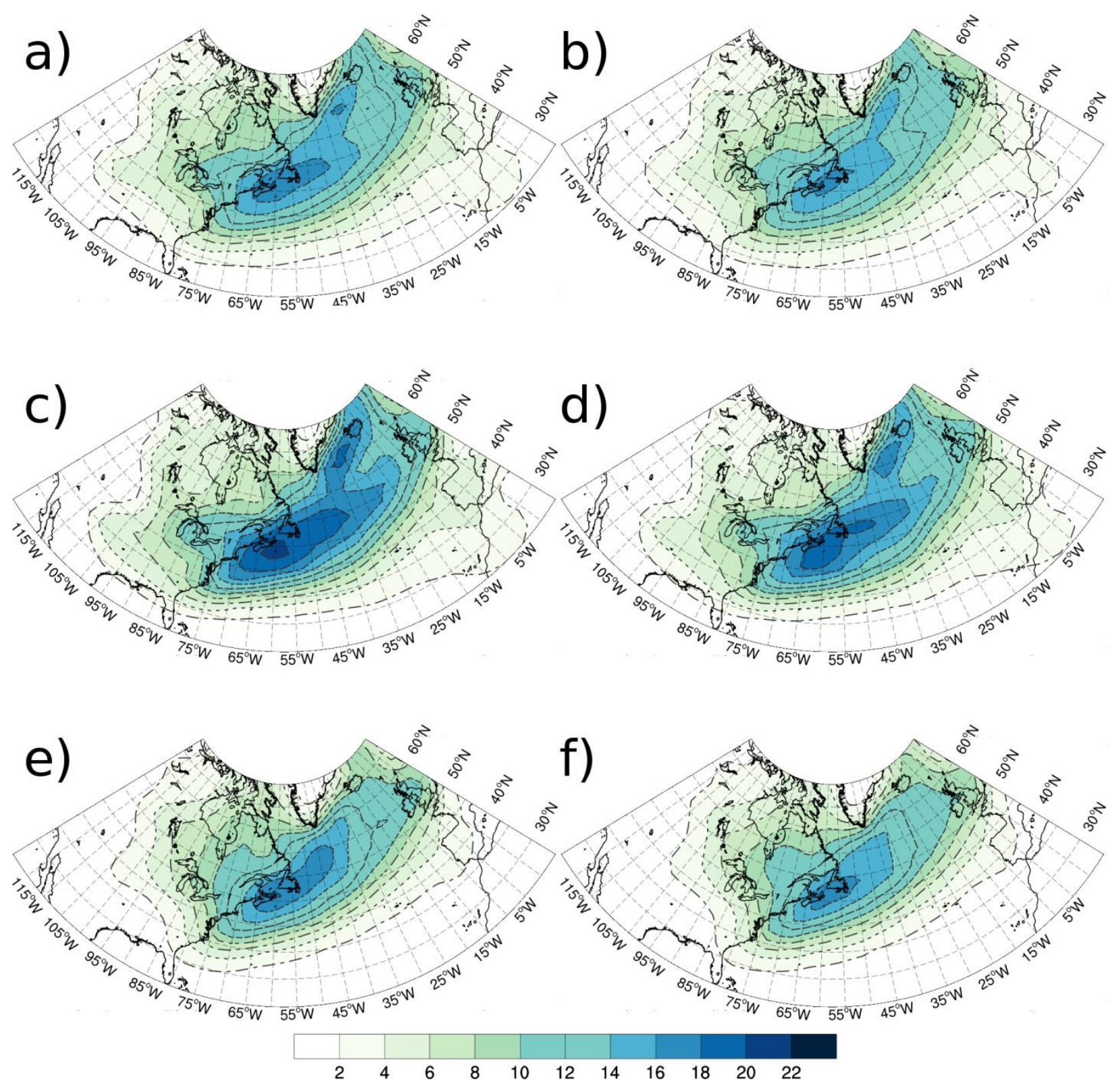

Figure 2. Track densities computed for the North Atlantic in (a,c,e) ERA5 and (b,d,f) CFSR/CFSv2, considering (a,b) all period (1979-2019), (c,d) DJF, and (e,f) JJA. The density unit is track per month per area, where the unit area is equivalent to a $5^{\circ}$ spherical cap $\left(10^{6} \mathrm{~km}^{2}\right)$. The contour interval is 2 tracks per month per area. 

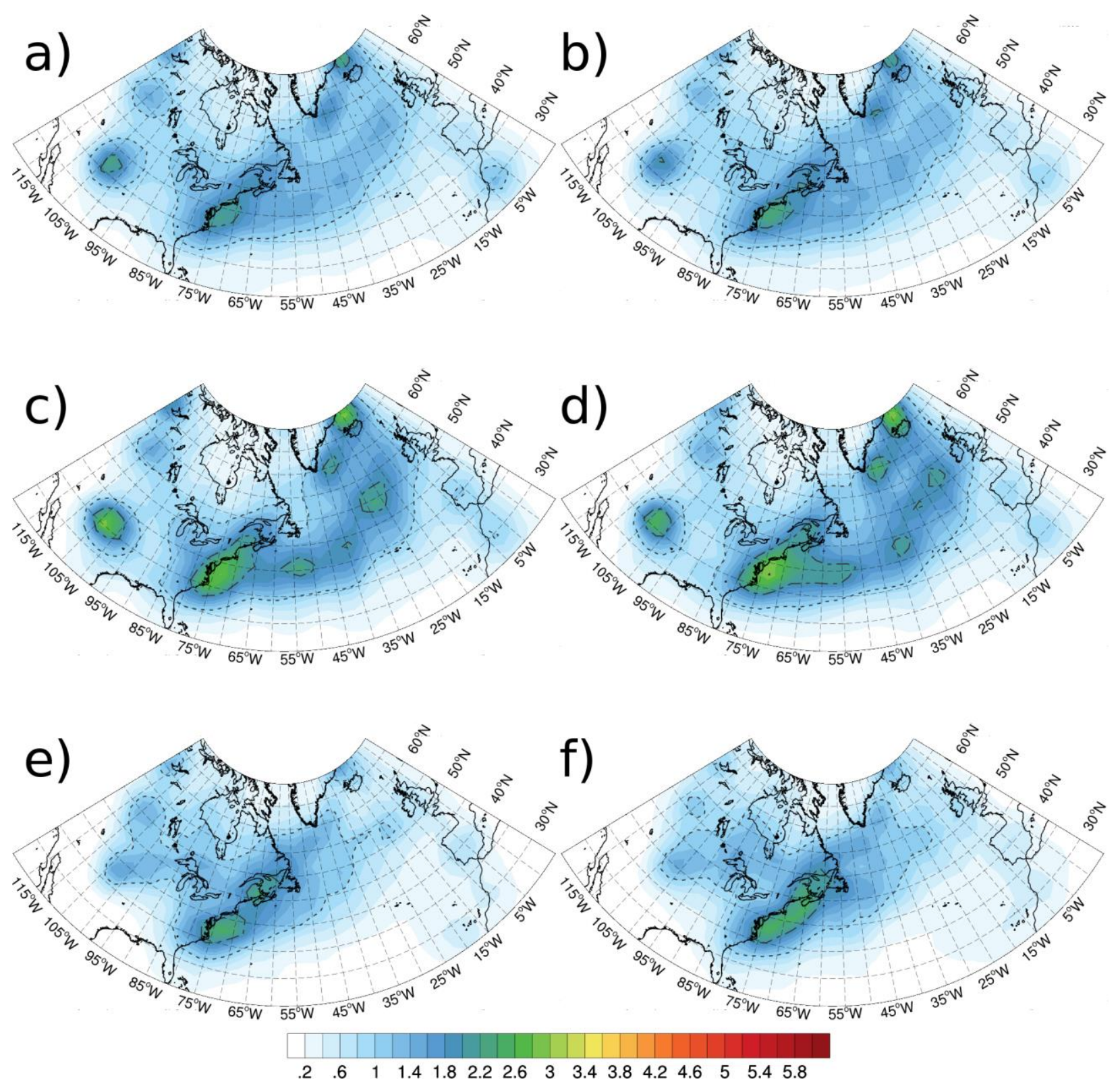

Figure 3. Genesis densities computed for the North Atlantic in (a,c,e) ERA5 and (b,d,f) CFSR/CFSv2, considering (a,b) all period (1979-2019), (c,d) DJF, and (e,f) JJA. The density unit is genesis per month per area, where the unit area is equivalent to a $5^{\circ}$ spherical cap $\left(10^{6} \mathrm{~km}^{2}\right)$. The contour interval is 1 genesis per month per area. 

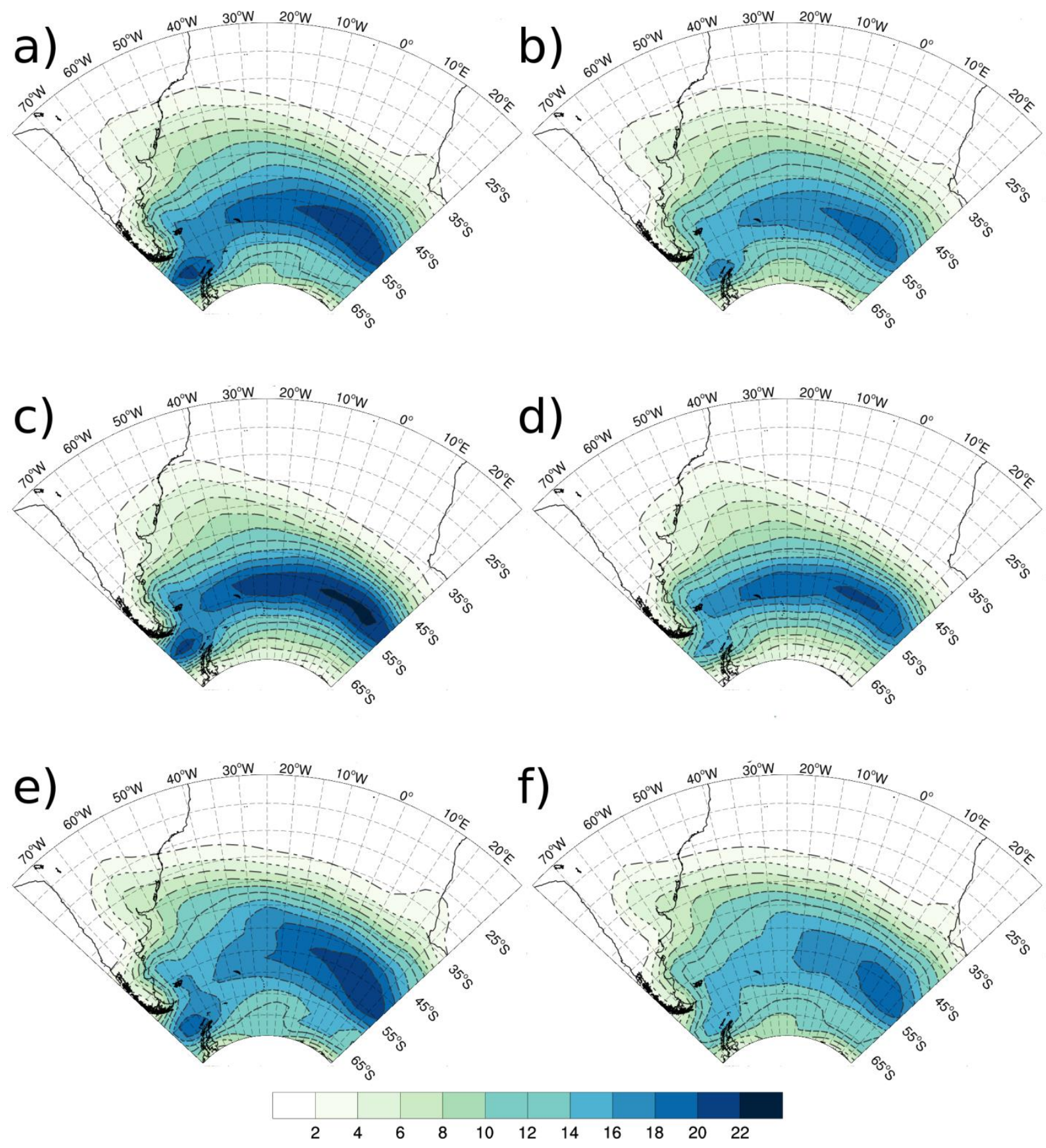

Figure 4. Track densities computed for the South Atlantic in (a,c,e) ERA5 and (b,d,f) CFSR/CFSv2, considering (a,b) all period (1979-2019), (c,d) DJF, and (e,f) JJA. The density unit is track per month per area, where the unit area is equivalent to a $5^{\circ}$ spherical cap $\left(10^{6} \mathrm{~km}^{2}\right)$. The contour interval is 2 tracks per month per area. 

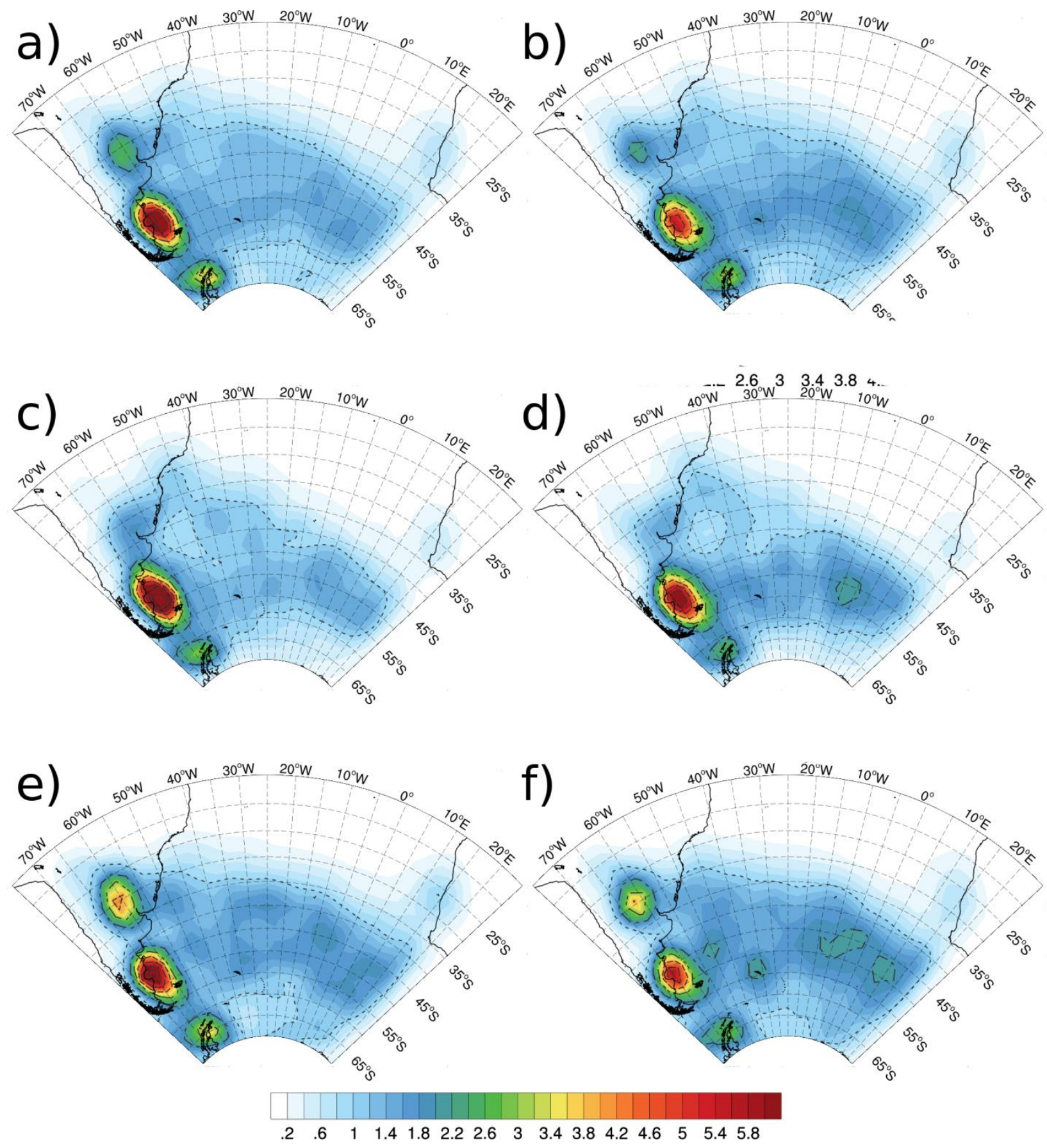

Figure 5. Genesis densities computed for the South Atlantic in (a,c,e) ERA5 and (b,d,f) CFSR/CFSv2, considering (a,b) all period (1979-2019), (c,d) DJF, and (e,f) JJA. The density unit is genesis per month per area, where the unit area is equivalent to a $5^{\circ}$ spherical cap $\left(10^{6} \mathrm{~km}^{2}\right)$. The contour interval is 1 genesis per month per area. 

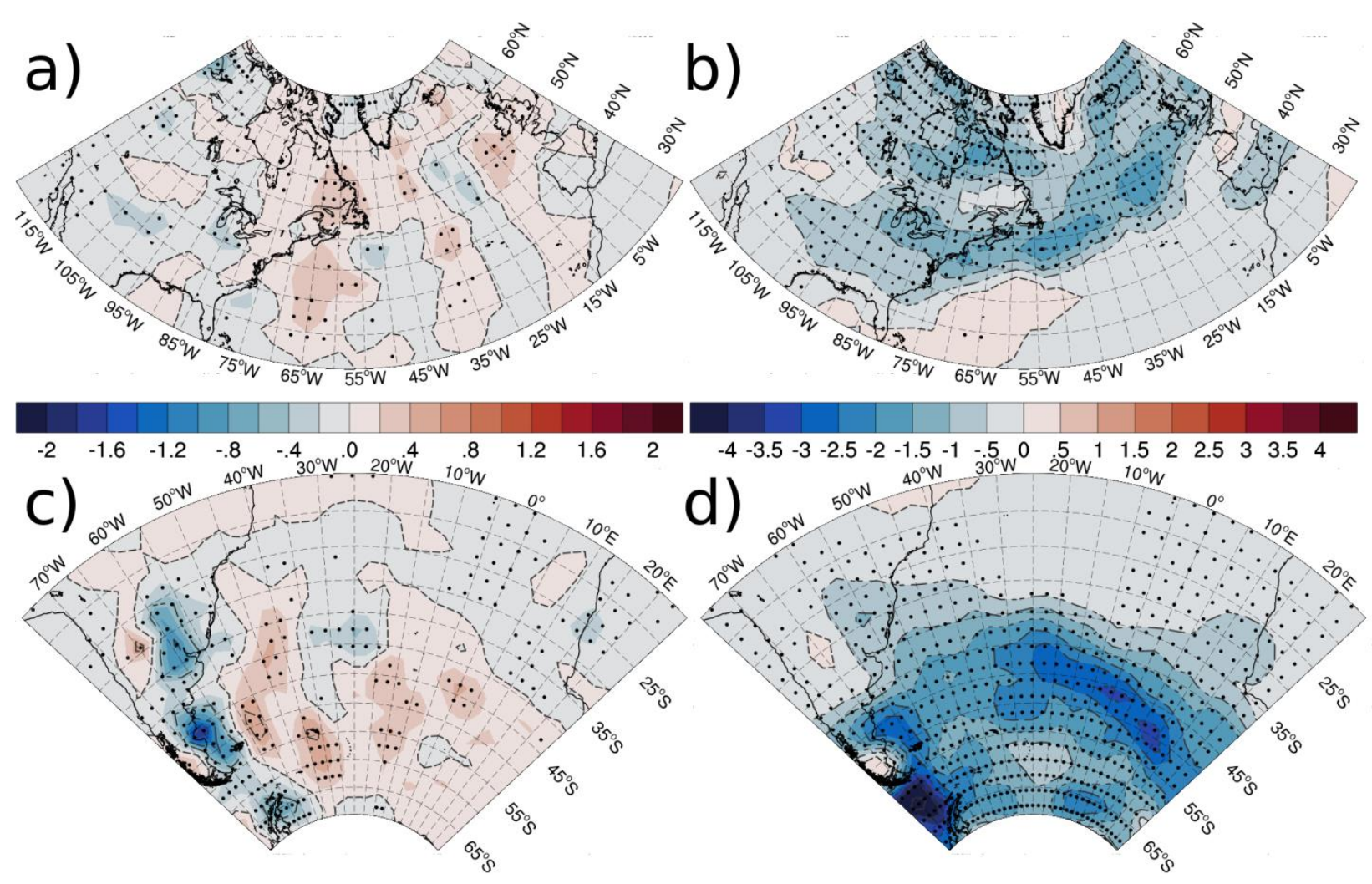

Figure 6. Densities differences in (a,b) DJF for the North Atlantic and (c,d) JJA for the South Atlantic, for the $(\mathrm{a}, \mathrm{c})$ cyclogenesis and $(\mathrm{b}, \mathrm{d})$ storm track. The density difference unit is cyclones/track per month per area, where the unit area is equivalent to a $5^{\circ}$ spherical cap $\left(10^{6} \mathrm{~km}^{2}\right)$. The dots represent grid points where the trend is significant within $99 \%$ confidence level, and the differences are CFSR/CFSv2 minus ERA5 considering 1979-2019 period. 

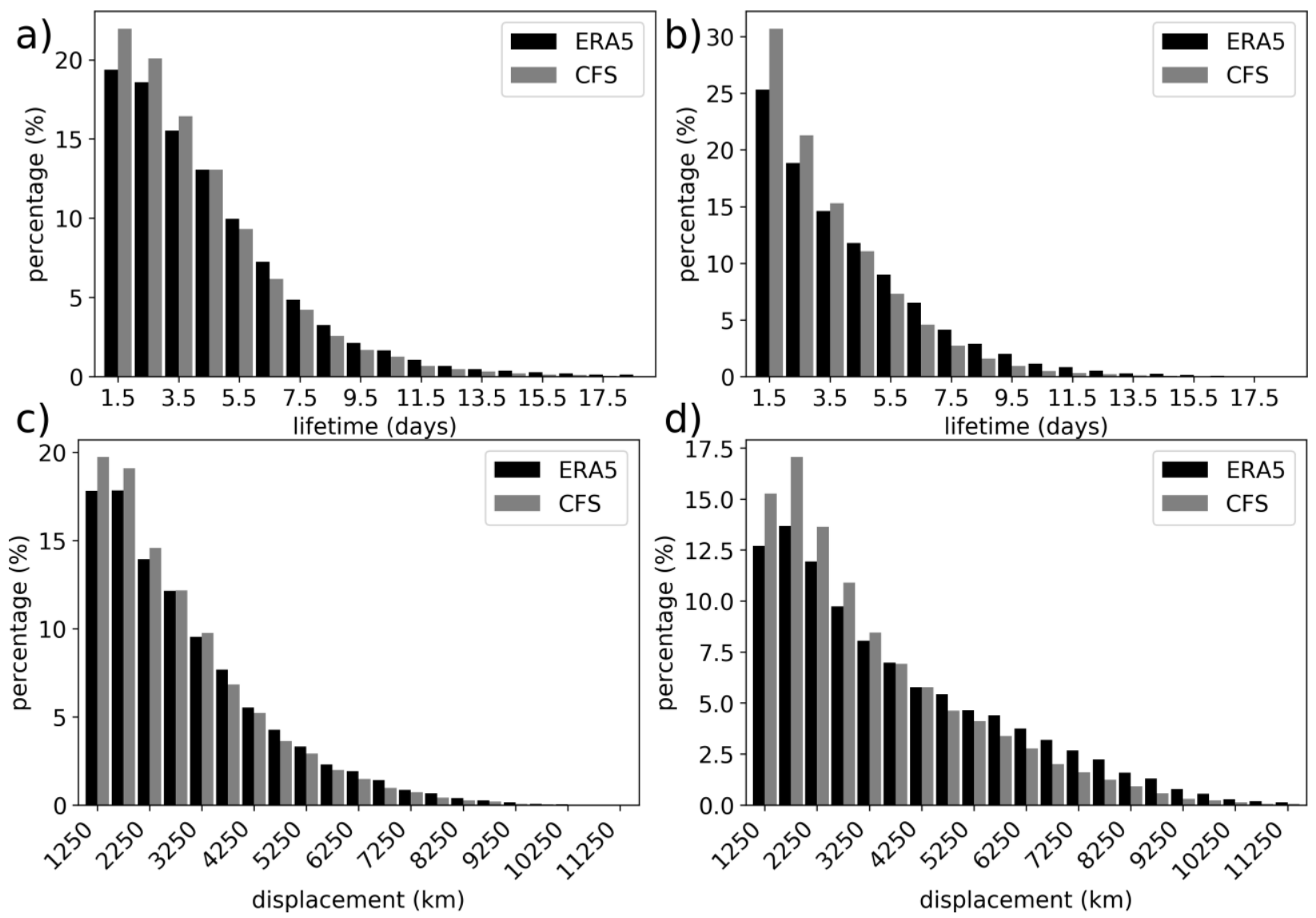

Figure 7 Histograms of cyclones (a,b) lifetime (days), and (c,d) displacement (km).for the (a,c) North Atlantic and (b,d) South Atlantic Oceans. The histograms were computed considering the whole 19792019 period for the ERA5 (black) and CFSR/CFSv2 (grey). 

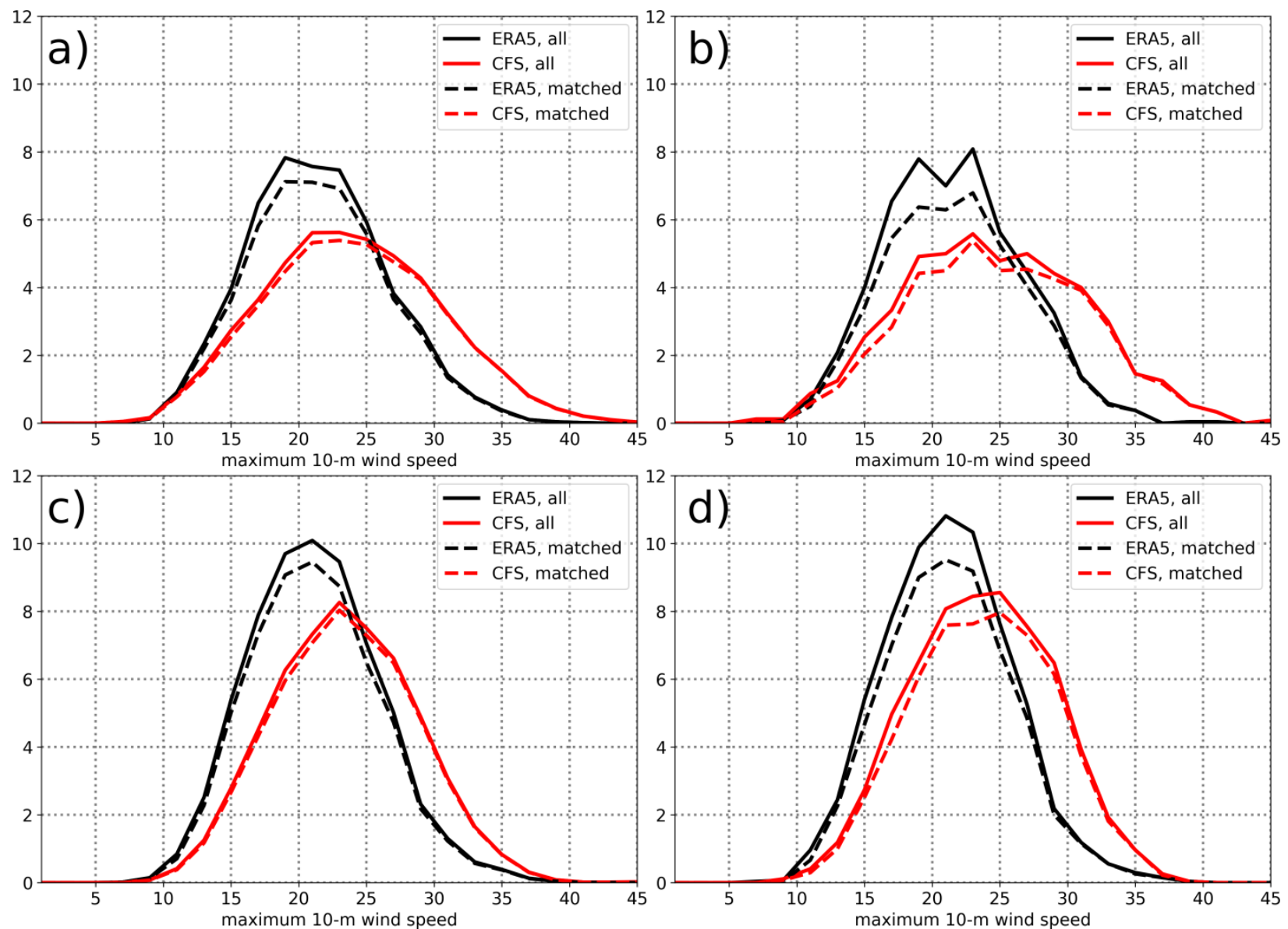

Figure 8. Cyclone's maximum 10-meters wind speed $\left(\mathrm{m} \mathrm{s}^{-1}\right)$ distribution for the $(\mathrm{a}, \mathrm{b})$ North Atlantic in DJF, and (c,d) South Atlantic in JJA, considering the period between (a,c) 1979 and 2019, and (b,d) April/2011 and 2019. ERA5 distributions are in black, and CFSR/CFSv2 are in red. The dashed lines are the distributions computed for the matched cyclones in each dataset. The y-axis is cyclone per month. 